Bull. Mater. Sci., Vol. 29, No. 5, October 2006, pp. 535-546. (c) Indian Academy of Sciences.

\title{
Structural and electrochemical behaviour of sputtered vanadium oxide films: oxygen non-stoichiometry and lithium ion sequestration
}

\author{
K J RAO*, B PECQUENARD ${ }^{\dagger}$, A GIES ${ }^{\dagger}$, A LEVASSEUR ${ }^{\dagger}$ and J ETOURNEAU ${ }^{\dagger}$ \\ Solid State and Structural Chemistry Unit, Indian Institute of Science, Bangalore 560 012, India \\ ${ }^{\dagger}$ ICMCB/ENSCPB, (CNRS-UPR 9048), Université Bordeaux I, 87 Avenue du Dr A Schweitzer, 33608 Pessac \\ Cedex, France
}

MS received 13 October 2006

\begin{abstract}
Structural and electrochemical aspects of vanadium oxide films recently reported from ICMCB/ ENSCPB have been examined using appropriate structural models. It is shown that amorphous films are nonstoichiometric as a result of pre-deposition decomposition of $\mathrm{V}_{2} \mathrm{O}_{5}$. It is proposed that the structure of amorphous films corresponds to a nanotextured mosaic of $\mathrm{V}_{2} \mathrm{O}_{5}$ and $\mathrm{V}_{2} \mathrm{O}_{4}$ regions. Lithium intercalation into these regions is considered to occur sequentially and determined by differences in group electronegativities. Open circuit voltages (OCV) have been calculated for various stoichiometric levels of lithiation using available thermodynamic data with approximate corrections. Sequestration of lithium observed in experiments is shown to be an interfacial phenomenon. $X$-ray photoelectron spectroscopic observation of the formation of $\mathrm{V}^{3+}$ even when $\mathrm{V}^{5+}$ has not been completely reduced to $\mathrm{V}^{4+}$ is shown to be entirely consistent with the proposed structural model and a consequence of initial oxygen nonstoichiometry. Based on the structural data available on $\mathrm{V}_{2} \mathrm{O}_{5}$ and its lithiated products, it is argued that the geometry of $\mathrm{VO}_{n}$ polyhedron changes from square pyramid to trigonal bipyramid to octahedron with increase of lithiation. A molecular orbital based energy band diagram is presented which suggests that lithiated vanadium oxides, $L i_{x} V_{2} O_{5}$, become metallic for high values of $x$.
\end{abstract}

Keywords. Amorphous films; vanadium oxide films; structural and electrochemical properties.

\section{Introduction}

Recently, Gies et al (2005) examined sputtered films of $\mathrm{V}_{2} \mathrm{O}_{5}$ obtained under different sputtering conditions and studied the electrochemical behaviour of the films during lithium ion intercalation-deintercalation reactions. The principal observations are as follows: (i) Sputtered films are crystalline when the sputtering gas mixture has $10 \%$ or higher oxygen content and are amorphous at lower than $10 \%$ oxygen, (ii) when no oxygen is present in the sputtering gas, the films obtained are not only amorphous but also contain $\sim 40 \%$ of vanadium as $\mathrm{V}^{4+}$. Various vanadium valence species have been quantitatively studied using high resolution X-ray photoelectron spectroscopy (XPS) measurements. On this basis the composition of the amorphous film has been found to be deficient in oxygen and the formula for the nonstoichiometric amorphous films has been assigned as $\mathrm{V}_{2} \mathrm{O}_{4 \cdot 6}$, (iii) low angle $\mathrm{X}$-ray scattering studies has revealed that the crystalline films grow with definite orientation, $\langle 001\rangle$ being perpendicular to the substrate surface, (iv) the X-ray diffraction (XRD) patterns do not reveal any change even when $\mathrm{Li}^{+}$ions are

*Author for correspondence (kjrao@sscu.iisc.ernet.in) intercalated up to $x=2 \cdot 0$ in $\mathrm{Li}_{x} \mathrm{~V}_{2} \mathrm{O}_{5}$ (ex situ diffraction studies were done and only a slight increase of $c$ parameter was noted). This is similar to the structural behaviour noted in the case of sodium vanadium bronzes, $\mathrm{Na}_{x} \mathrm{~V}_{2} \mathrm{O}_{5}$, up to $x=1.7$ (Pereira-Ramos et al 1988), (v) amorphous and crystalline thin films were found to exhibit remarkable differences in microstructure as observed in scanning electron microscopy (SEM); amorphous film is constituted of large blocks with smooth surface while crystalline film consists of fine rods of nanometric dimensions with no clear orientation, (vi) in their electrochemical behaviour also crystalline and amorphous films are found to be quite distinct. Crystalline films exhibit four distinguishable voltage plateaus in the first cycle which may arguably be attributed to $(\alpha+\varepsilon),(\varepsilon+\delta),(\delta+\gamma)$ and $(\gamma+\omega)$ biphasic systems. But in second and subsequent cycling the plateaus disappear and the galvanostatic plots of voltage vs $x$ (intercalate $\mathrm{Li}^{+}$) appear as simple smooth curves decreasing from the highest to the lowest voltage in charge-discharge cycles (see figure 1 which will be discussed further later). On the other hand, amorphous films exhibit only a continuously decreasing curve with two regions of moderate and steep slopes (at somewhat lower voltage and with $x>1$ ) during the first discharge. But during first de-intercalation and subsequent cycles it exhibits voltage beha- 

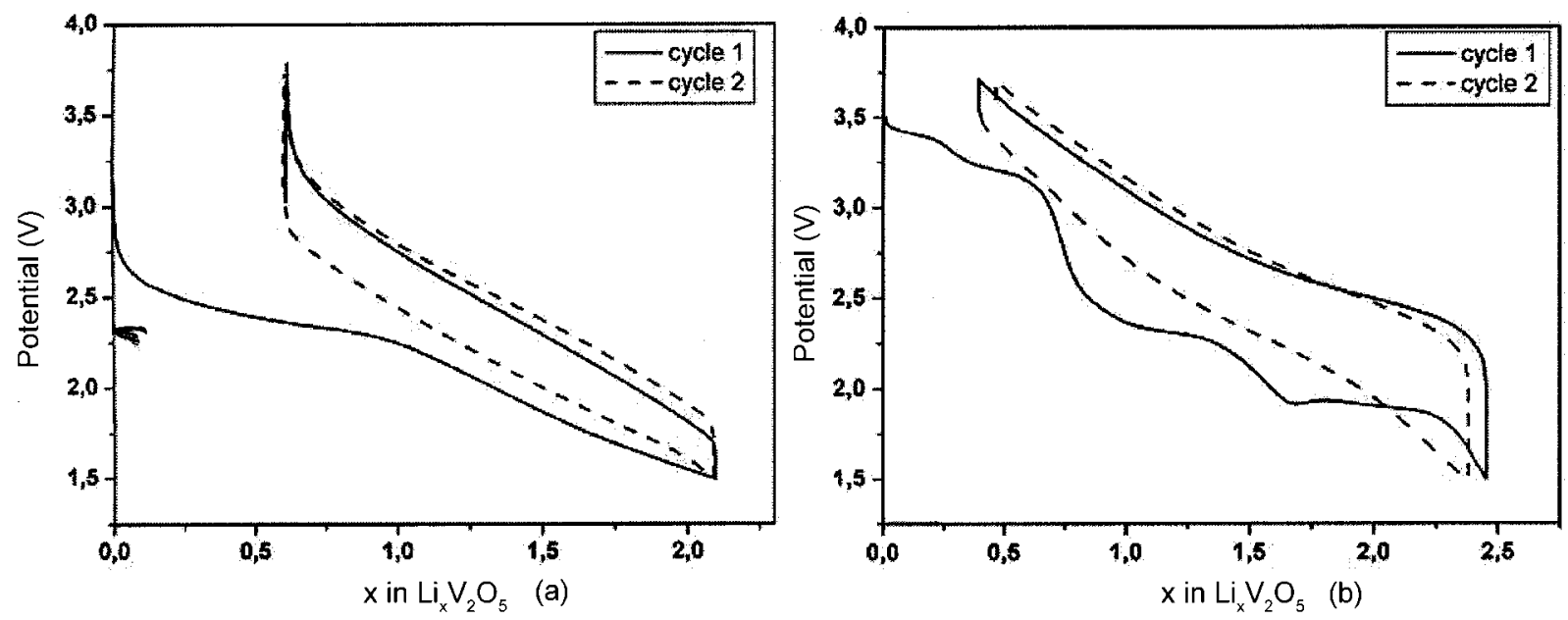

Figure 1. Galvanostatic charge-discharge cycling traces of amorphous $\mathrm{Li}_{x} \mathrm{~V}_{2} \mathrm{O}_{4 \cdot 6}(\mathbf{a})$ and crystalline $\mathrm{Li}_{x} \mathrm{~V}_{2} \mathrm{O}_{5}(\mathbf{b})$ films: note the plateaus in the case of crystalline films and the extent of sequestered lithium content.

viour similar to the crystalline films (figure 1). However, it is found that a certain amount of $\mathrm{Li}^{+}$is retained in the films which cannot be de-intercalated. This retention of $\mathrm{Li}^{+}$is observed in some crystalline films also, but the non de-intercalable $\mathrm{Li}^{+}$is much less. Such crystalline films contained substantial quantity (17\%) of $\mathrm{V}^{4+}$ present in them as a result of sputtering conditions. The non de-intercalable lithium, which we will refer to as "sequestrated" $\mathrm{Li}^{+}$ions, seems to occur whenever there is oxygen nonstoichiometry due to the formation of $\mathrm{V}^{4+}$ in as-sputtered films, (vii) after the first lithium intercalation cycling, both crystalline and amorphous films become electrochemically amorphous. Crystalline films exhibit high initial capacity values in the first cycle but the capacity drops to essentially flat values in subsequent galvanostatic measurements. However, capacity stability of amorphous films is markedly better than that of crystalline films and remains stable even after several charge-discharge cycles (Gies et al 2005), (viii) an unreported but related observation about the films is that the electrodes exhibit significant electronic conductivity when the lithium concentration in $\mathrm{Li}_{x} \mathrm{~V}_{2} \mathrm{O}_{5}$ increases well above 1, (ix) $\mathrm{X}$-ray photoelectron spectroscopy (XPS) studies (figure 2) have revealed that reduction of vanadium by lithium intercalation is not strictly hierarchical in the sense all of $\mathrm{V}^{5+}$ is not reduced to $\mathrm{V}^{4+}$ before appearance of $\mathrm{V}^{3+}$. It is observed in both amorphous and crystalline films. Simultaneous presence of vanadium in all three valence states is curious and $(\mathrm{x})$ although $\mathrm{V}^{4+}$ is present in the as-prepared amorphous films, the initial ratio of $\left(\mathrm{V}^{4+} / \mathrm{V}^{5+}\right)$ can be restored even after 30 electrochemical cycles while in crystalline films, the original state is not restored as revealed by the presence of $\mathrm{V}^{4+}$ in such films; the reversibility is not complete.

The above observations further confirm the rich variety of physicochemical phenomenon associated with vanadium oxides. Vanadium oxidation state in oxides span from +2 to +5 (although +2 state is not relevant to the present studies) with $\mathrm{O} / \mathrm{V}$ ratio ranging from $1-2 \cdot 5$. In fact, oxygen to vanadium ratio has been found (Zavalij and Whittingham 1999) to reach up to $3 . \mathrm{V}_{2} \mathrm{O}_{3}$ is the first member of homologous series of oxides (Schwingenschlogl et al 2003) of the formula, $\mathrm{V}_{n} \mathrm{O}_{2 n-1}$ and the end member is $\mathrm{VO}_{2}$ $(n \rightarrow \infty)$. Vanadium is generally found in oxygen coordination of 5 or 6 although tetrahedral coordination is favoured in orthovanadates (Zavalij and Whittingham 1999). The 5-coordination vanadium-oxygen polyhedron is either in square pyramidal $(s p)$ or trigonal bipyramidal $(t b p)$ geometries. In 6-coordination, the polyhedron seems to be present only in octahedral (distorted or regular) geometry. In low oxidation states, vanadium prefers to be present in octahedral coordination while in high $(=5)$ oxidation state, it prefers $s p$ or $t b p$ coordination. Oxides with low oxidation state of vanadium are more ionic and exhibit insulator-metal transitions (Schwingenschlogl et al 2003). The formation of homologous series of oxides and the high range of $\mathrm{O} / \mathrm{V}$ ratio observed in vanadium oxides (Zavalij amd Whittingham 1999) imply the high propensity of vanadium oxides towards nonstoichiometry and their ability to sustain multiple valence states in the same compound.

In this back drop, we present here a structural model and examine the various experimental observations referred to above and reported in Gies et al (2005). We also show that indeed the electrochemical and X-ray spectroscopic (XPS) observations are completely consistent with the structural chemistry of vanadium oxide films. We will also attempt to show that the observed voltages in the galvanostatic discharge-charge cycling can be predicted approximately using available thermochemical data and empirical estimates of the required corrections. 


\section{Crystallized}
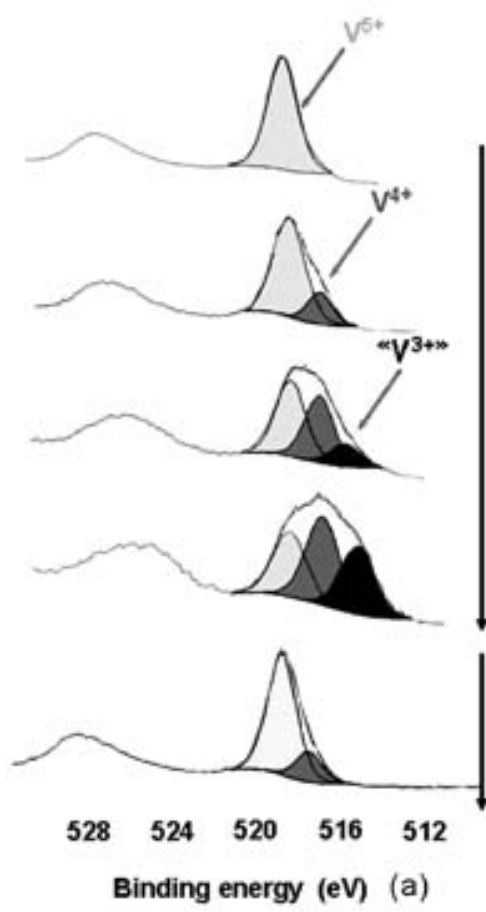

Amorphous

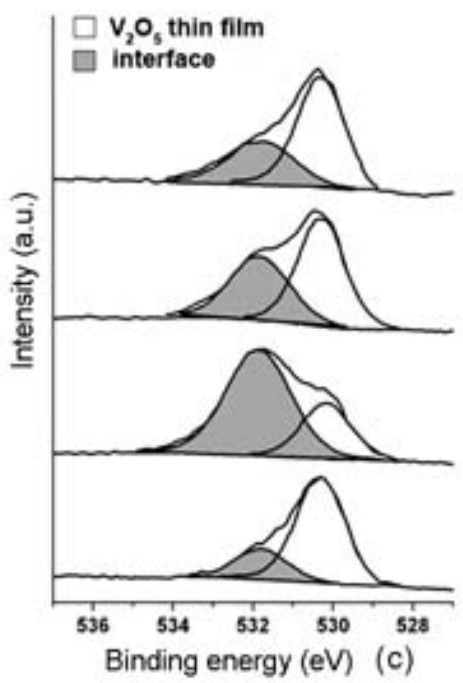

As-deposited

\section{Amorphous}

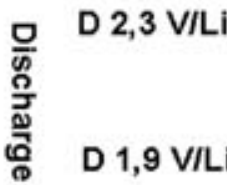

D 1,5 V/Li
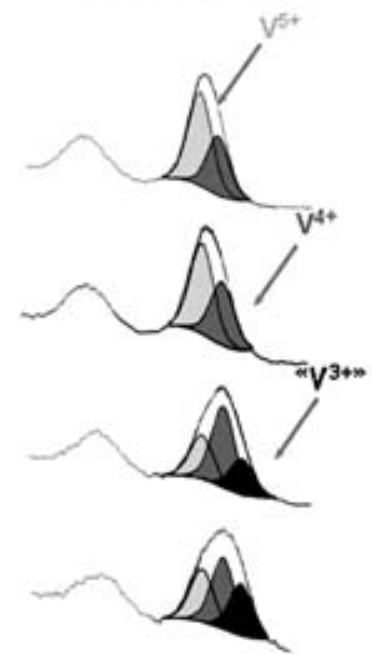

옴

C $3,7 \mathrm{VILi}$

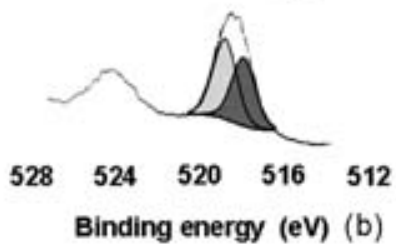

Crystallized

$\mathrm{V}_{2} \mathrm{O}_{\mathrm{s}}$ thin film

interface

as-deposited

D: $2.3 \mathrm{~V} / \mathrm{Li}$

D: $1.5 \mathrm{~V} / \mathrm{Li}$

C: $3.7 \mathrm{~V} / \mathrm{Li}$

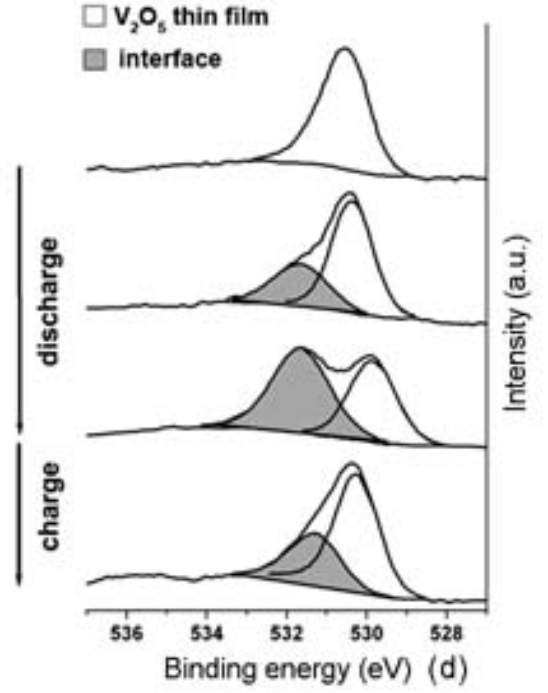

Figure 2. XPS spectra of $\mathrm{Li}_{x} \mathrm{~V}_{2} \mathrm{O}_{5}$ and $\mathrm{Li}_{x} \mathrm{~V}_{2} \mathrm{O}_{4 \cdot 6}$ films. (a) and (b) are the spectra associated with $\mathrm{V}\left(2 p_{3 / 2}\right)$ levels of crystalline and amorphous films, respectively. (c) and (d) are the $\mathrm{O}(1 s)$ spectra for the crystalline and amorphous films, respectively.

\section{Structural model for $\mathrm{V}_{2} \mathrm{O}_{5}$ sputtered films}

The XRD patterns of crystalline $\mathrm{V}_{2} \mathrm{O}_{5}$ films (Gies et al 2005) obtained with Bragg-Brentano geometry suggest that the structure of $\mathrm{V}_{2} \mathrm{O}_{5}$ in the films is orthorhombic, $\alpha$ $\mathrm{V}_{2} \mathrm{O}_{5}(P m m n)$. The structure reveals preferred growth orientation and the growth occurs in the $c(\langle 001\rangle)$ direction of the crystal. XRD studies also show that the ortho- 
rhombic structure does not undergo changes on lithiation, only the $c$ parameter increases slightly. This is in contrast to the observation made in bulk $\mathrm{V}_{2} \mathrm{O}_{5}$ in which different phases have been found to develop (Galy et al 1971; Enjalbert and Galy 1986; Cocciantelli et al 1992; Delmas et al 1994). These phases have been characterized as $\alpha, \varepsilon, \delta$ and $\omega$ in addition to $\gamma$ (and also $\gamma^{\prime}$ ) (West et al 1995; Rocquefelte et al 2003). It is now fairly well established that $\mathrm{V}_{2} \mathrm{O}_{5}$ in all its structures consist of $\left[\mathrm{VO}_{5}\right]$ square pyramids (sp) which form different types of layers (Zavalij and Whittingham 1999). The chemical structure of the unit corresponds (Clark 1968) to $\left[\mathrm{VOO}_{1 / 2} \mathrm{O}_{3 / 3}\right]$; one (apical) oxygen is bonded exclusively to the vanadium atom, one is in corner shared geometry, and the three other oxygens are in edge shared positions. The $s p$ units in the layers are organized as [up-up/down-down] sequences (uudd) in Zavalij-Whittingham (1999) notation. The interlayer distances are large and the apical oxygens in any layer is positioned in such a way that the $\left[\mathrm{VO}_{5}\right]$ square pyramid of the layer about it can be considered as a distorted octahedron. A little glide of the layers can distort the [ $\left.\mathrm{VO}_{5}\right]$ $s p$ into $t b p$ geometry while a little closing up of the layers can give rise to $\left[\mathrm{VO}_{6}\right]$ octahedra. Reduction of vanadium from $\mathrm{V}^{5+}$ to $\mathrm{V}^{4+}$ with attendant loss of oxygen leads to the formation of $\mathrm{VO}_{2}$ which has a rutile structure. Rutile structure renders all oxygens structurally similar to each other (Müller 1993; Wells 1995) and three coordinated to vanadium and vanadium in itself attains octahedral coordination.

In the present studies, we have two distinct situations: in the crystalline films, the composition is $\mathrm{V}_{2} \mathrm{O}_{5}$ and it is stoichiometric and in the amorphous films, it is $\mathrm{V}_{2} \mathrm{O}_{4 \cdot 6}$ and it is nonstoichiometric. The nonstoichiometry of the latter is due to presence of $\mathrm{V}^{4+}$ and $\mathrm{V}^{5+}$ in the films (Gies et al 2005) in the ratio $\mathrm{V}^{4+} / \mathrm{V}^{5+}=4 / 6\left(\right.$ or $40 \% \mathrm{~V}^{4+}$ ). During electrochemical lithiation, $\mathrm{V}^{n+}$ is reduced to $\mathrm{V}^{(n-1)+}$. The number of oxygens in the structure remains undisturbed. The resulting imbalance in $\left[\mathrm{VO}_{n}\right]$ electrical neutrality is compensated by the charge on $\mathrm{Li}^{+}$and the electrical neutrality is achieved over a slightly larger volume of $\mathrm{LiVO}_{n}$. In the crystalline phase the charge on vanadium in the $s p$ units decreases upon lithiation and we propose that in the process the layers gradually get closer and the structure gradually evolves from $s p \rightarrow t b p \rightarrow \mathrm{O}$ (octahedral) geometry. The $s p$ geometry may not change directly to $\mathrm{O}$ because the just introduced $\mathrm{Li}^{+}$in the interlayer region disturbs asymmetrically the oxygen positions in $s p$ units and one of the oxygen atoms is slightly pulled into interlayer region. This has consequences in the gradual evolution of electronic band structure which we will discuss later in this paper.

In the case of amorphous films we have both $\mathrm{V}^{5+}$ and $\mathrm{V}^{4+}$ in the composition. This, we feel gives rise to regions of $\mathrm{V}_{2} \mathrm{O}_{4}$ interwoven with $\mathrm{V}_{2} \mathrm{O}_{5}$ regions. We propose that these regions are of nanometric size. We also propose that in $\mathrm{V}_{2} \mathrm{O}_{4}, \mathrm{~V}^{4+}$ attains octahedrality through the formation of both $\left[\mathrm{VO}_{2 / 2} \mathrm{O}_{4 / 4}\right]$ and $\left[\mathrm{VO}_{6 / 3}\right]$ (as in rutile) units in the structure. This is because vanadium has an inherent propensity to form octahedron upon reduction to $\mathrm{V}^{4+}$. This is readily achieved through the closing up of the $\mathrm{V}_{2} \mathrm{O}_{5}$ layers which is also assisted by the deficiency of oxygen. These structural changes definitely contribute to the loss of long range order and the film of composition $\mathrm{V}_{2} \mathrm{O}_{4 \cdot 6}$ is, therefore, necessarily amorphous. In summary, the structural model proposed here considers (i) crystalline films are (generally) stoichiometric and on lithiation lead to gradual evolution of $\left[\mathrm{VO}_{5}\right]$ structure from $s p$ to $t b p$ to $\mathrm{O}_{h}$ symmetries and (ii) amorphous films contain nanometric regions of $\mathrm{V}_{2} \mathrm{O}_{4}$ interwoven with $\mathrm{V}_{2} \mathrm{O}_{5}$ regions. $\mathrm{V}_{2} \mathrm{O}_{4}$ regions consist of $\left[\mathrm{VO}_{6}\right]$ octahedra. We examine the observation of Gies et al (2005) on the basis of the above structural model.

\section{Experimental}

\subsection{Composition and structures of crystalline and amorphous films}

The first observation of Gies et al (2005) is that low rates of sputtering and high oxygen partial pressure leads to crystalline stoichiometric $\mathrm{V}_{2} \mathrm{O}_{5}$ films. But relatively high total pressures of sputtering gases and low oxygen partial pressures (oxygen free sputtering gas) lead to nonstoichiometric amorphous films. This is understandable because higher sputtering gas pressures lead to higher bombardment rates and hence to an increase of 'local' temperature on the substrate. This temperature can be very high and leads to $\mathrm{V}_{2} \mathrm{O}_{5}$ decomposition. $\mathrm{V}_{2} \mathrm{O}_{5}$ decomposes reversibly as $\mathrm{V}_{2} \mathrm{O}_{5} \rightleftharpoons \mathrm{V}_{2} \mathrm{O}_{4}+1 / 2 \mathrm{O}_{2}$. For this decomposition reaction the equilibrium constant, $K$, is given by

$$
\frac{\left[\mathrm{V}_{2} \mathrm{O}_{4}\right]}{\left[\mathrm{V}_{2} \mathrm{O}_{5}\right]} \mathrm{Po}_{2}^{1 / 2},
$$

and the reaction free energy is given by $-R T \ln K$ or $-R T \ln \left(\mathrm{Po}_{2}{ }^{1 / 2}\right)=-R T / 2 \ln \left(\mathrm{Po}_{2}\right)$. Alternately, the change in free energy is given by $\left[\Delta G^{\circ}\left(\mathrm{V}_{2} \mathrm{O}_{5}\right)-\Delta G^{\circ}\left(\mathrm{V}_{2} \mathrm{O}_{4}\right)\right]$ at $T$. If the local temperature reaches about $900 \mathrm{~K}$ which is below the melting temperatures of both $\mathrm{V}_{2} \mathrm{O}_{4}$ and $\mathrm{V}_{2} \mathrm{O}_{5}$, we can calculate $\mathrm{Po}_{2}$ from known $\Delta G^{\circ}$ values (JANAF Tables). $\Delta G^{\circ}=-1163 \cdot 9\left(\mathrm{~V}_{2} \mathrm{O}_{4}\right)-(-1222 \cdot 6)\left(\mathrm{V}_{2} \mathrm{O}_{5}\right)=41 \cdot 3 \mathrm{~kJ} / \mathrm{mole}$. Therefore, $\ln \left(\mathrm{Po}_{2}\right)=-\left[41.3 \times 10^{3}\right] /[8.3 \times 900]=-4.8$ and $\mathrm{Po}_{2}=1.58 \times 10^{-5}$ atm $\cong 1.6 \mathrm{~Pa}$.

Therefore, the pressure of $\mathrm{O}_{2}$ on the bombarded $\mathrm{V}_{2} \mathrm{O}_{5}$ target is itself of the order of $1.6 \mathrm{~Pa}$. When the oxygen partial pressure in the plasma gas is lower than this value, significant portion of the target $\mathrm{V}_{2} \mathrm{O}_{5}$ arrives at the substrate as $\mathrm{V}_{2} \mathrm{O}_{4}$. This explains the presence of $40 \% \mathrm{~V}^{4+}$ in the amorphous films obtained with no oxygen in the plasma gas. Also at $2.5 \mathrm{~Pa}$ sputtering gas pressure $10 \% \mathrm{O}_{2}$ corresponds to $0.35 \mathrm{~Pa}$ of oxygen partial pressure. This is probably less than the equilibrium $\mathrm{O}_{2}$ partial pressure and as a result even the crystalline $\mathrm{V}_{2} \mathrm{O}_{5}$ film sputtered at $2 \cdot 5 \mathrm{~Pa}$ has resulted with significant $\mathrm{V}^{4+}$ concentration. 
When the proportion of $\mathrm{V}^{4+}$ is low, the resulting $\mathrm{V}_{2} \mathrm{O}_{4}$ is perhaps easily integrated into $\mathrm{V}_{2} \mathrm{O}_{5}$ structure creating defects as a result of $\mathrm{V}_{2} \mathrm{O}_{4}$ solubility in $\mathrm{V}_{2} \mathrm{O}_{5}$.

Further, during sputtering $\left[\mathrm{VO}_{5}\right]$ square pyramids land on the substrate with their bases first as this provides increased Van der Waals bonding to the surface (four basal oxygens from the $s p$ units). This appears to be the driving force for the orientation effect observed by Gies et al (2005). $\langle 001\rangle$ is perpendicular to the plane of (uudd) layers of $\mathrm{V}_{2} \mathrm{O}_{5}$ in the $\alpha-\mathrm{V}_{2} \mathrm{O}_{5}$ structure.

During lithiation intercalated $\mathrm{Li}^{+}$ions occupy interlayer positions in the crystalline $\mathrm{V}_{2} \mathrm{O}_{5}$. The actual reaction can be represented as

$$
\begin{aligned}
& {\left[\mathrm{VOO}_{1 / 2} \mathrm{O}_{3 / 3}\right]^{\circ}+\mathrm{Li}^{\circ} \rightarrow\left[\mathrm{V}^{\mathrm{V}} \mathrm{OO}_{1 / 2} \mathrm{O}_{3 / 3}\right]^{-}} \\
& +\mathrm{Li}^{+} \rightarrow\left[\left(\mathrm{V}^{\mathrm{IV}} \mathrm{OO}_{1 / 2} \mathrm{O}_{3 / 3}\right)^{-} \mathrm{Li}^{+}\right]^{\circ}
\end{aligned}
$$

$\mathrm{Li}^{+}$has the effect of pulling together the layers in the process of occupying an octahedral position. As lithiation progresses, the reduction of the charge on vanadium and the presence of lithium in interlayer region tend to smear out the bond angle and bond length asymmetries and the vanadium site becomes a nearly regular octahedron. In fact, there have been approaches in the literature which treat $\mathrm{V}_{2} \mathrm{O}_{5}$ as oxygen $f c c$ packing (Eyert and Hock 1998). Thus, there are 5 moles of oxygens in $\mathrm{V}_{2} \mathrm{O}_{5}$ which produce 5 moles of octahedral holes. Of these 2 moles are occupied by $\mathrm{V}^{5+}$ ions and 3 moles are available for lithium occupation. Therefore, lithiation in thin films is unlikely to bring about drastic structural changes but only affects the interlayer distances consistent with the observation that only the $c$-parameter increases to a small extent.

Layered oxides in their nascent state and under suitable conditions of temperature and pressure give rise to nanorods, tubes and scrolls (Muhr et al 2000; Chandrappa et al 2002; Wang et al 2004). In the present case the condition required by $\mathrm{V}_{2} \mathrm{O}_{5}$ thin films seems to be that even as the small sheets of $\mathrm{V}_{2} \mathrm{O}_{5}$ are formed, small patches of them are able to set free from the sites on which the $a b$ planes of $\mathrm{V}_{2} \mathrm{O}_{5}$ are anchored on the substrate. When their thicknesses are a few tens of $\AA$, the relative magnitude of the $\mathrm{Si}(110)-\mathrm{V}_{2} \mathrm{O}_{5}$ (100) interplanar interaction (Van der Waals) become weaker in comparison to intra $\mathrm{V}_{2} \mathrm{O}_{5}$ sheet interactions. As a result the pieces of these sheets lift off and fold up and give rise to rod like morphology of the crystalline films. The amorphous films on the other hand are already a nanocomposite (textured on a nanoscale) of the $\mathrm{V}_{2} \mathrm{O}_{5}$ and $\mathrm{V}_{2} \mathrm{O}_{4}$ regions. The oxygen deficiency of the films compared to $\mathrm{V}_{2} \mathrm{O}_{5}$ composition induces extensive cohesion in the process of sharing available oxygens. This helps to build a three-dimensional structure with the observed smooth glassy (disordered) block-like morphology.

\subsection{Electrochemical behaviour}

The most interesting feature of the crystalline films has been their electrochemical behaviour (figure 1). With lithium intercalation four plateaus are observed during first discharge process. But during the first charging process itself these plateaus disappear and a smooth line behaviour of the voltages characteristic of amorphous films is observed. The films are perhaps electrochemically and structurally become amorphous after the first discharge process itself (Delmas et al 1991). The four potential plateaus occur at $3.4 \mathrm{~V}$ (up to $\mathrm{Li}=0 \cdot 2$ ), $3 \cdot 2 \mathrm{~V}$ (up to $\mathrm{Li}=0 \cdot 6$ ), $2 \cdot 3 \mathrm{~V}$ (up to $\mathrm{Li}=1 \cdot 2$ ) and $1.8 \mathrm{~V}$ (up to $\mathrm{Li}=2 \cdot 3$ ), respectively. The plateaus are smoothly connected and do not reflect any sharp transitions. The observed open circuit voltages (OCV) may be compared with those of bulk $\mathrm{V}_{2} \mathrm{O}_{5}$ in which clear crystallographic phases seem to form corresponding to the plateaus and are associated with fairly sharp transitions from region to region: $\alpha$-phase $(3.4 \mathrm{~V}$; $x=0.4), \varepsilon$-phase $(3.25 \mathrm{~V} ; x=1), \delta$-phase $(2.5 \mathrm{~V} ; x=2)$ and $\omega$-phase $(2 \cdot 2 \mathrm{~V} ; x=3)$, where $x$ is the degree (molar) of intercalation of $\mathrm{Li}^{+}$in $\mathrm{Li}_{x} \mathrm{~V}_{2} \mathrm{O}_{5}$ (see also table 1). Highest OCV have been recorded by $\gamma^{\prime}$-phase $(3.6 \mathrm{~V}$ and $x$ up to $0 \cdot 4)$. The $\gamma$-phase OCV plateaus continue through $\gamma$ and $\xi$ phases to $\omega$ phase regions. The crystallographic differences are weak but do exist. The $3.4 \mathrm{~V}, 3 \cdot 2 \mathrm{~V}, 2.3 \mathrm{~V}$ and $1.8 \mathrm{~V}$ plateaus are nearly comparable in values to the $3.4 \mathrm{~V}, 3.25 \mathrm{~V}, 2.5 \mathrm{~V}$ and $2.2 \mathrm{~V}$ observed in crystalline $\mathrm{V}_{2} \mathrm{O}_{5}$ films although the OCVs of $\delta$ and $\omega$-phases are significantly lower for the films compared to the bulk values. Rocquefelte et al (2003) have used theoretically calculated energies for the various phases in place of free energies and successfully accounted for the OCVs of various lithiated phases. The calculations involve several approximations such as using $\Delta U$ in place of $\Delta G^{\circ}$. Density functional theory (DFT) energies (using generalized gradient approximation (GGA) and a pseudo-potential for core shell valence interactions) are difficult to evaluate for the nonstoichiometric $\mathrm{V}_{2} \mathrm{O}_{4.6}$. The two facts viz. that the films do not reveal all the phases identified in bulk $\mathrm{V}_{2} \mathrm{O}_{5}$ and that the amorphous films are nonstoichiometric, indicate that we can only make some approximate evaluation of the observed OCVs of the film using empirical approaches.

We may note in this connection that $\mathrm{Li}^{+}$ions occupy the octahedral positions and $\mathrm{V}^{5+}$ ions $s p$ positions. But [ $\left.\mathrm{VO}_{5}\right]$ units gradually evolve into $\left[\mathrm{VO}_{6}\right]$ units of octahedral geometry without significant local $\mathrm{V}-\mathrm{O}$ bond disturbances by mere shortening of interlayer distances. During intercalation, an electron is transferred to $\mathrm{V}^{5+}$ resulting in $\mathrm{V}^{5+} \rightarrow \mathrm{V}^{4+}$ conversion and the overall reaction is in essence $\left[\mathrm{V}_{2} \mathrm{O}_{5}\right]+\mathrm{Li} \rightarrow 1 / 2\left[\mathrm{~V}_{2} \mathrm{O}_{4}\right]+1 / 2 \mathrm{Li}_{2} \mathrm{O}$. Since $\mathrm{V}-\mathrm{O}$ structure is not altered, the product of the reaction is in reality $\left[\mathrm{V}_{2} \mathrm{O}_{5}\right]^{-}+\mathrm{Li}^{+}$. But the free energies for the two reactions are in principle different. The free energies for the first reaction can be obtained from the free energies of formation of the oxides. But the second one is what is needed and is not readily available. We may visualize that a second step is involved in the first reaction in which $1 / 2 \mathrm{O}^{2-}$ from $1 / 2 \mathrm{Li}_{2} \mathrm{O}\left(\equiv \mathrm{Li}^{+}+1 / 2 \mathrm{O}^{2-}\right)$ is integrated into $1 / 2\left[\mathrm{~V}_{2} \mathrm{O}_{4}\right]$ to give $1 / 2\left[\mathrm{~V}_{2} \mathrm{O}_{5}\right]^{-}$. The required data are, however, difficult 
Table 1a. Thermodynamic and electronegativity data used in the calculation of free energies.

\begin{tabular}{lcc}
\hline Oxide & $-\Delta G^{\circ}$ at $298 \cdot 1 \mathrm{~K}(\mathrm{~kJ} / \mathrm{mole})$ & $-\Delta G^{\circ}$ at $900 \mathrm{~K}(\mathrm{~kJ} / \mathrm{mole})$ \\
\hline $\mathrm{V}_{2} \mathrm{O}_{5}$ & 1419.35 & 1163.9 \\
$\mathrm{~V}_{2} \mathrm{O}_{4}$ & 1318.45 & 1122.6 \\
$\mathrm{~V}_{2} \mathrm{O}_{3}$ & 1139.04 & - \\
$\mathrm{Li}_{2} \mathrm{O}$ & $562 \cdot 1$ & - \\
\hline
\end{tabular}

Table 1b. Thermodynamic and electronegativity data used in the calculation of group/molecular electronegativities.

\begin{tabular}{|c|c|c|c|c|c|c|c|}
\hline Atom & $\begin{array}{c}\text { Electro- } \\
\text { negativity, } \chi\end{array}$ & Group & $\begin{array}{c}\text { Electro- } \\
\text { negativity, } \chi\end{array}$ & Group & $\begin{array}{c}\text { Electro- } \\
\text { negativity, } \chi\end{array}$ & Group & $\begin{array}{c}\text { Electro- } \\
\text { negativity, } \chi\end{array}$ \\
\hline $\mathrm{Li}$ & 0.98 & $\mathrm{~V}_{2} \mathrm{O}_{5}$ & 2.782 & $\mathrm{Li}_{2} \mathrm{~V}_{2} \mathrm{O}_{5}$ & 2.440 & $\mathrm{Li}_{3} \mathrm{~V}_{2} \mathrm{O}_{5}$ & 2.032 \\
\hline $\mathrm{V}$ & 1.63 & $\mathrm{~V}_{2} \mathrm{O}_{4}$ & $2 \cdot 687$ & $\mathrm{Li}_{2} \mathrm{~V}_{2} \mathrm{O}_{4}$ & $2 \cdot 322$ & & \\
\hline \multirow[t]{2}{*}{$\mathrm{O}$} & 3.44 & $\mathrm{~V}_{2} \mathrm{O}_{3}$ & $2 \cdot 552$ & $\mathrm{Li}_{2} \mathrm{~V}_{2} \mathrm{O}_{5}$ & $2 \cdot 204$ & $\mathrm{Li}_{2} \mathrm{O}$ & 1.489 \\
\hline & & $\mathrm{Li}_{0 \cdot 5} \mathrm{~V}_{2} \mathrm{O}_{5}$ & $2 \cdot 586$ & $\mathrm{Li}_{2} \mathrm{~V}_{2} \mathrm{O}_{4}$ & $2 \cdot 085$ & & \\
\hline
\end{tabular}

Example of a calculation: $\chi \mathrm{LiV}_{2} \mathrm{O}_{5}=\left[\chi_{(\mathrm{Li})} \cdot \chi_{(\mathrm{V})}^{2} \cdot \chi_{(\mathrm{O})}^{5}\right]^{1 / 8}=2 \cdot 440$.

to obtain. We represent the electrochemical reaction in two steps

$$
\begin{aligned}
& \mathrm{Li}+\mathrm{V}_{2} \mathrm{O}_{5} \leftrightarrow 1 / 2 \mathrm{Li}_{2} \mathrm{O}+1 / 2 \mathrm{~V}_{2} \mathrm{O}_{4}+1 / 2 \mathrm{~V}_{2} \mathrm{O}_{5}: \\
& \text { free energy change }=\Delta G^{\circ}(1), \\
& 1 / 2 \mathrm{Li}_{2} \mathrm{O}+1 / 2 \mathrm{~V}_{2} \mathrm{O}_{4}+1 / 2 \mathrm{~V}_{2} \mathrm{O}_{5} \rightarrow \mathrm{Li}^{+}+\mathrm{V}_{2} \mathrm{O}_{5}^{-} \\
& \left(\equiv \mathrm{LiV}_{2} \mathrm{O}_{5}\right): \text { free energy change }=\Delta G^{\circ}(2) .
\end{aligned}
$$

The value of $\Delta G^{\circ}(2)$ is presumably lower than $\Delta G^{\circ}(1)$, because it only involves structural integration of $\mathrm{O}^{2-}$ ion. $\Delta G^{\circ}(1)$ is given by

$$
\begin{aligned}
& \Delta G^{\circ}(1)=1 / 2 \Delta G^{\circ}\left(\mathrm{V}_{2} \mathrm{O}_{4}\right)+1 / 2 \Delta G^{\circ}\left(\mathrm{Li}_{2} \mathrm{O}\right) \\
& -1 / 2 \Delta G^{\circ}\left(\mathrm{V}_{2} \mathrm{O}_{5}\right) .
\end{aligned}
$$

In order to evaluate $\Delta G^{\circ}(2)$, we search for a general physical property covariant with the free energy of the reaction. A very general and convenient property is the electronegativity. As $\mathrm{V}_{2} \mathrm{O}_{5}$ changes to $\mathrm{LiV}_{2} \mathrm{O}_{5}$ the group electronegativity drops to a lower value. It is well known that energy change can be related to electronegativity changes in the spirit of Pauling electronegativities. We approximate this energy as $k \Delta \chi^{2}$, where $\Delta \chi=\left[\chi_{\mathrm{V}_{2} \mathrm{O}_{5}}-\right.$ $\left.\chi_{\mathrm{LiV}_{2} \mathrm{O}_{5}}\right]$, is the change in electronegativity. Upon further lithiation, $\chi$ decreases further and further from the value of $\chi_{\mathrm{LiV}_{2} \mathrm{O}_{5}}$. Therefore, on a heuristic basis we choose $\Delta G^{\circ}(2)=k \Delta \chi^{2}$ and fix the value of $k$ by requiring that $\Delta G^{\circ}\left(\Delta G^{\circ}(1)+\Delta G^{\circ}(2)\right)$, for the reaction, $\mathrm{Li}+\mathrm{V}_{2} \mathrm{O}_{5} \rightarrow$ $\mathrm{LiV}_{2} \mathrm{O}_{5}$ be equal to $-n E F$, where $E$ is the experimentally measured potential. We have found that $k=700 \mathrm{~kJ} / \mathrm{mole}$ is a good approximation. The value of $\Delta G^{\circ}$ of $\mathrm{V}_{2} \mathrm{O}_{5}$, $\mathrm{V}_{2} \mathrm{O}_{4}, \mathrm{~V}_{2} \mathrm{O}_{3}$ and $\mathrm{Li}_{2} \mathrm{O}$ for the standard thermodynamic state are taken from JANAF tables. $\Delta \chi$ values were evaluated from the molecular electronegativities calculated by the procedure of Sanderson,

$$
\chi=\left(\Pi \chi_{i}^{m}\right)^{1 / \Sigma m_{j}},
$$

where $i$ represents the atom in the group and $m$ the number of the $i^{\text {th }}$ type of atom (Sanderson 1976, 1983). These $\chi$ values (table $1 \mathrm{~b}$ ), along with the $\Delta G^{\circ}$ values of the oxides (table 1a) are listed above. The assumed reaction steps are listed in table 2. The calculated and experimentally measured values of potential for the crystalline (bulk) $\mathrm{Li}_{x} \mathrm{~V}_{2} \mathrm{O}_{5}$ are summarized in table 3 . We have chosen to calculate the voltage values for $\mathrm{LiV}_{2} \mathrm{O}_{5}(\varepsilon), \mathrm{Li}_{2} \mathrm{~V}_{2} \mathrm{O}_{5}(\delta), \mathrm{Li}_{3} \mathrm{~V}_{2} \mathrm{O}_{5}(\omega)$ and $\mathrm{Li}_{0.5} \mathrm{~V}_{2} \mathrm{O}_{5}(\alpha)$ phase compositions since good experimental data is available for comparison (Rocquefelte et al 2003).

In the $\Delta \chi$ calculations we have assumed that the $\mathrm{Li}$ intercalated product can be treated as neutral units like $\mathrm{Li}_{x} \mathrm{~V}_{2} \mathrm{O}_{5}$ in which atoms are governed by electronegativity equalization. The process involves stabilization of the chemical entities and hence lowering of free energy.

Table 2 reveals that the use of $k=700 \mathrm{~kJ} / \mathrm{mole}$ gives quite good values for $\varepsilon$ and $\delta$ phase voltages. In the case of $\omega$-phase, calculated values are somewhat higher than the known value. But for the $\alpha$-phase, the difference is quite high. This represents the situation where small degree intercalation causes significant lowering of free energy, the reason for which is not clear to us at this stage. Even if the entropy term of distributing $0.5 \mathrm{~N} \mathrm{~V}^{4+}$ on $2 \mathrm{~N}$ vanadium sites and $0.5 \mathrm{~N} \mathrm{Li}^{+}$ions on available $3 \mathrm{~N}$ octahedral sites are considered, the $T \Delta S$ term does not contribute more than a couple of $\mathrm{kJ} / \mathrm{mole}$ at $300 \mathrm{~K}$ and the magnitude of $\Delta G$ indicated by the voltage of the $\alpha$-phase is several times this value. Therefore, we tentatively assume that $700 \Delta \chi^{2}$ compensates the value of $\Delta G$ underestimates resulting from the use of $\Delta G^{\circ}(1)$ alone in the voltage equation.

The voltage observed in amorphous $\mathrm{V}_{2} \mathrm{O}_{4 \cdot 6}$ films may be calculated in the same manner as in crystalline $\mathrm{V}_{2} \mathrm{O}_{5}$ films. As stated earlier, we treat $\mathrm{V}_{2} \mathrm{O}_{4 \cdot 6}$ films as nanotextured $\mathrm{V}_{2} \mathrm{O}_{4}-\mathrm{V}_{2} \mathrm{O}_{5}$ mosaic. Therefore, $\mathrm{Li}$ intercalation takes place as if lithium is exposed to $\mathrm{V}_{2} \mathrm{O}_{4}$ and $\mathrm{V}_{2} \mathrm{O}_{5}$ nanoregions with slightly different electronegativities. $\mathrm{Li}$ atoms, therefore, intercalate into regions of higher electronegativity preferentially at any point during intercalation. The thin film composition of $\mathrm{V}_{2} \mathrm{O}_{4 \cdot 6}$, is $40 \% \mathrm{~V}_{2} \mathrm{O}_{4}$ and $60 \% \mathrm{~V}_{2} \mathrm{O}_{5}\left(0.4 \mathrm{~V}_{2} \mathrm{O}_{4}, 0.6 \mathrm{~V}_{2} \mathrm{O}_{5}\right)$ and the two are assu- 
Table 2. Lithiation reactions for the crystalline $\mathrm{V}_{2} \mathrm{O}_{5}$ films. EMF expressions.

\begin{tabular}{|c|c|c|}
\hline Electrode reactions and $\Delta G^{\circ}(1)$ expressions $\Delta G^{\circ}(1)(\mathrm{kJ})$ & $\begin{array}{c}\Delta \chi \\
\Delta G^{\circ}(2)=700 \Delta \chi^{2} \\
\text { (for all reactions) }\end{array}$ & $\begin{array}{c}E(\text { volts }) \\
\Delta G^{\circ}=\Delta G^{\circ}(1)+\Delta G^{\circ}(2)\end{array}$ \\
\hline $\mathrm{V}_{2} \mathrm{O}_{5} \rightarrow \mathrm{LiV}_{2} \mathrm{O}_{5}(\varepsilon$-phase $)$ & $\chi\left(\mathrm{V}_{2} \mathrm{O}_{5}\right)-\chi\left(\mathrm{LiV}_{2} \mathrm{O}_{5}\right)$ & $-\Delta G^{\circ} / \mathrm{F}$ \\
\hline \multicolumn{3}{|l|}{$\begin{array}{l}\mathrm{Li}+\mathrm{V}_{2} \mathrm{O}_{5} \rightarrow 1 / 2 \mathrm{Li}_{2} \mathrm{O}+1 / 2 \mathrm{~V}_{2} \mathrm{O}_{4}+1 / 2 \mathrm{~V}_{2} \mathrm{O}_{5} \rightarrow \mathrm{LiV}_{2} \mathrm{O}_{5} \\
\Delta G^{\circ}(1)=1 / 2\left[\Delta G^{\circ}\left(\mathrm{Li}_{2} \mathrm{O}\right)+\Delta G^{\circ}\left(\mathrm{V}_{2} \mathrm{O}_{4}\right)-\Delta G^{\circ}\left(\mathrm{V}_{2} \mathrm{O}_{5}\right)\right]\end{array}$} \\
\hline $\mathrm{LiV}_{2} \mathrm{O}_{5} \rightarrow \mathrm{Li}_{2} \mathrm{~V}_{2} \mathrm{O}_{5}(\delta$-phase $)$ & $\chi\left(\mathrm{LiV}_{2} \mathrm{O}_{5}\right)-\chi\left(\mathrm{Li}_{2} \mathrm{~V}_{2} \mathrm{O}_{5}\right)$ & $-\Delta G^{\circ} / 2 \mathrm{~F}$ \\
\hline \multicolumn{3}{|l|}{$\begin{array}{l}\mathrm{Li}+\mathrm{LiV}_{2} \mathrm{O}_{5} \rightarrow \mathrm{Li}_{2} \mathrm{O}+\mathrm{V}_{2} \mathrm{O}_{4} \rightarrow \mathrm{Li}_{2} \mathrm{~V}_{2} \mathrm{O}_{5} \\
\Delta G^{\circ}(1)=\left[\Delta G^{\circ}\left(\mathrm{Li}_{2} \mathrm{O}\right)+\Delta G^{\circ}\left(\mathrm{V}_{2} \mathrm{O}_{4}\right)-\Delta G^{\circ}\left(\mathrm{V}_{2} \mathrm{O}_{5}\right)\right]\end{array}$} \\
\hline $\mathrm{Li}_{2} \mathrm{~V}_{2} \mathrm{O}_{5} \rightarrow \mathrm{Li}_{3} \mathrm{~V}_{2} \mathrm{O}_{5}(\omega$-phase $)$ & $\chi\left(\mathrm{Li}_{2} \mathrm{~V}_{2} \mathrm{O}_{5}\right)-\chi\left(\mathrm{Li}_{3} \mathrm{~V}_{2} \mathrm{O}_{5}\right)$ & $-\Delta G^{\circ} / 3 \mathrm{~F}$ \\
\hline \multicolumn{3}{|l|}{$\begin{array}{l}\mathrm{Li}+\mathrm{Li}_{2} \mathrm{~V}_{2} \mathrm{O}_{5} \rightarrow 3 / 2 \mathrm{Li}_{2} \mathrm{O}+1 / 2 \mathrm{~V}_{2} \mathrm{O}_{3}+1 / 2 \mathrm{~V}_{2} \mathrm{O}_{4} \rightarrow \mathrm{Li}_{3} \mathrm{~V}_{2} \mathrm{O}_{5} \\
\Delta G^{\circ}(1)=1 / 2\left[3 \Delta G^{\circ}\left(\mathrm{Li}_{2} \mathrm{O}\right)+\Delta G^{\circ}\left(\mathrm{V}_{2} \mathrm{O}_{3}\right)+\Delta G^{\circ}\left(\mathrm{V}_{2} \mathrm{O}_{4}\right)-2 \Delta G^{\circ}\left(\mathrm{V}_{2} \mathrm{O}_{5}\right)\right]\end{array}$} \\
\hline $\mathrm{V}_{2} \mathrm{O}_{5} \rightarrow \mathrm{Li}_{0.5} \mathrm{~V}_{2} \mathrm{O}_{5}(\alpha$-phase $)$ & $\chi\left(\mathrm{V}_{2} \mathrm{O}_{5}\right)-\chi\left(\mathrm{Li}_{0.5} \mathrm{~V}_{2} \mathrm{O}_{5}\right)$ & $-\Delta G^{\circ} / 0 \cdot 5 \mathrm{~F}$ \\
\hline $\begin{array}{l}0 \cdot 5 \mathrm{Li}+\mathrm{V}_{2} \mathrm{O}_{5} \rightarrow 0 \cdot 25 \mathrm{Li}_{2} \mathrm{O}+0 \cdot 25 \mathrm{~V}_{2} \mathrm{O}_{4}+0 \cdot 75 \mathrm{~V}_{2} \mathrm{O}_{5} \\
\Delta G^{\circ}(1)=0 \cdot 25\left[\Delta G^{\circ}\left(\mathrm{Li}_{2} \mathrm{O}\right)+\Delta G^{\circ}\left(\mathrm{V}_{2} \mathrm{O}_{4}\right)-\Delta G^{\circ}\left(\mathrm{V}_{2} \mathrm{O}_{5}\right)\right]\end{array}$ & & \\
\hline
\end{tabular}

Table 3. Calculated voltages for lithium intercalated $\mathrm{V}_{2} \mathrm{O}_{5}$ and the corresponding observed voltages for bulk crystalline $\mathrm{Li}_{x} \mathrm{~V}_{2} \mathrm{O}_{5}$.

\begin{tabular}{llccccc}
\hline $\mathrm{Li}_{x} \mathrm{~V}_{2} \mathrm{O}_{5}$ phase & Formula & $\begin{array}{c}\text { Observed } \\
\text { voltage }(\mathrm{V})\end{array}$ & $\begin{array}{c}\text { Observed } \\
-\Delta G^{\circ}(\mathrm{kJ})\end{array}$ & $\begin{array}{c}\text { Calculated } \\
-\Delta G^{\circ}(\mathrm{kJ})\end{array}$ & $\begin{array}{c}\text { Calculated } \\
-\Delta G^{\circ}(2)(\mathrm{kJ})\end{array}$ & $\begin{array}{c}\text { Calculated } \\
\text { voltage }(\mathrm{V})\end{array}$ \\
\hline$\varepsilon$ & $\mathrm{LiV}_{2} \mathrm{O}_{5}$ & $3 \cdot 25$ & $313 \cdot 6$ & $312 \cdot 5$ & $81 \cdot 9$ & $3 \cdot 23$ \\
$\delta$ & $\mathrm{Li}_{2} \mathrm{~V}_{2} \mathrm{O}_{5}$ & $2 \cdot 50$ & $472 \cdot 8$ & $500 \cdot 1$ & $38 \cdot 9$ & $2 \cdot 59$ \\
$\omega$ & $\mathrm{Li}_{3} \mathrm{~V}_{2} \mathrm{O}_{5}$ & $2 \cdot 20$ & $636 \cdot 8$ & $673 \cdot 2$ & $20 \cdot 7$ & $2 \cdot 32$ \\
$\alpha$ & $\mathrm{Li}_{0.5} \mathrm{~V}_{2} \mathrm{O}_{5}$ & $3 \cdot 4$ & $164 \cdot 1$ & $142 \cdot 2$ & $26 \cdot 9$ & $2 \cdot 95$ \\
\hline
\end{tabular}

med to be present as two distinguishable nanoregions for lithium intercalation. The electronegativities have been calculated for $\mathrm{V}_{2} \mathrm{O}_{4}$ and its several lithiated compositions in the same manner as for $\mathrm{V}_{2} \mathrm{O}_{5}$ and its lithiated compositions. These values of $\chi$ are listed in table $1 . \Delta G^{\circ}(2)$ values are also calculated as $700 \Delta \chi^{2}$ for each stage.

Since $\mathrm{V}_{2} \mathrm{O}_{5}$ has a higher value of $\chi(2.782)$ than $\mathrm{V}_{2} \mathrm{O}_{4}$ (2.270), lithium intercalation occurs first into $\mathrm{V}_{2} \mathrm{O}_{5}$. We have calculated the free energy changes for stoichiometric values of $\mathrm{Li}$ intercalation $(x=1,2$ and 3$)$ into both $\mathrm{V}_{2} \mathrm{O}_{5}$ and $\mathrm{V}_{2} \mathrm{O}_{4}$ regions. The assumed reaction steps, the free energy and voltage expressions are given in table 4 . The calculated and observed voltages are listed in table 5 . The different valence species of vanadium expected to be present in the films at various stages of intercalation are also indicated in table 5. In actual situation while lithiation occurs alternately into $\mathrm{V}_{2} \mathrm{O}_{5}$ and $\mathrm{V}_{2} \mathrm{O}_{4}$ regions and in that order, it may occur at much smaller steps of increase of lithium content so that it is quasi-continuous. But the steps shown in table 3 are only illustrative of our approach to understand the process of lithium intercalation into the system consisting of $\mathrm{V}_{2} \mathrm{O}_{5}$ and $\mathrm{V}_{2} \mathrm{O}_{4}$ regions. The driving force for intercalation is the $\Delta \chi\left(\chi \mathrm{Li}_{x} \mathrm{~V}_{2} \mathrm{O}_{4 / 5}-\chi \mathrm{Li}\right)$ in the system; higher the $\Delta \chi$, greater is the propensity of Li to react and intercalate. The calculated voltages for the amorphous films are uniformly higher than the observed voltages when one considers the first discharge cycle. But the voltages (given in brackets in the table) observed during the second cycle match reasonably well. In view of the fact that there is no other procedure available for such calculations, we consider the present heuristic and tentative approach as gratifying.

\subsection{Simultaneous presence of $V^{5+}, V^{4+}$ and $V^{3+}$}

The most notable consequence of the postulated electrode reaction scheme is seen in the last column of table 3 . That is, $\mathrm{V}^{3+}$ appears in the system even before $\mathrm{V}^{5+}$ has been completely reduced to $\mathrm{V}^{4+}$. This also occurs at a significantly lower value of $x$ than in the crystalline film which contains only $\mathrm{V}_{2} \mathrm{O}_{5}$ to start with. In order to understand the reason, let us calculate more precisely when lithium begins to enter $\mathrm{V}_{2} \mathrm{O}_{4}$ regions according to the model because $\mathrm{V}^{3+}$ formation is a product of reduction of $\mathrm{V}^{4+}$ in $\mathrm{V}_{2} \mathrm{O}_{4}$. The $\chi$ value of $\mathrm{Li}_{x} \mathrm{~V}_{2} \mathrm{O}_{5}$ decreases with increasing $x$. For some smaller value of $x, \chi\left(\mathrm{Li}_{x} \mathrm{~V}_{2} \mathrm{O}_{5}\right)$ becomes equal to $\chi\left(\mathrm{V}_{2} \mathrm{O}_{4}\right)$. Above this value of $x$, intercalation begins to occur in a sea-saw manner into both regions of $\mathrm{Li}_{x} \mathrm{~V}_{2} \mathrm{O}_{5}$ and $\mathrm{Li}_{y} \mathrm{~V}_{2} \mathrm{O}_{4}$ in which $x$ and $y$ are necessarily unequal and vary at different rates. This is the reason why the system releases $\Delta G$ in a continuous manner and $E$ decreases con- 
Table 4. Lithiation reactions for the amorphous films, the EMF expressions and the expected vanadium valence species at the end of lithiation.

\begin{tabular}{|c|c|c|c|}
\hline Electrode reactions and $\Delta G^{\circ}(1)$ expression & $\Delta \chi$ & $\begin{array}{c}E(\mathrm{~V}) \\
\Delta G^{\circ}=\Delta G^{\circ}(1)+\Delta G^{\circ}(2) \\
\Delta G^{\circ}(2)=700 \Delta \chi^{2}\end{array}$ & $\begin{array}{l}\text { Comments on V } \\
\text { valence species }\end{array}$ \\
\hline $\begin{array}{l}\mathrm{V}_{2} \mathrm{O}_{4 \cdot 6} \rightarrow \mathrm{Li}_{0 \cdot 6} \mathrm{~V}_{2} \mathrm{O}_{4 \cdot 6} \\
0 \cdot 6 \mathrm{Li}+\mathrm{V}_{2} \mathrm{O}_{4 \cdot 6}\left(\equiv 0 \cdot 4 \mathrm{~V}_{2} \mathrm{O}_{4}+0 \cdot 6 \mathrm{~V}_{2} \mathrm{O}_{5}\right) \rightarrow \\
0 \cdot 4 \mathrm{~V}_{2} \mathrm{O}_{4}+0 \cdot 3 \mathrm{Li}_{2} \mathrm{O}+0 \cdot 3 \mathrm{~V}_{2} \mathrm{O}_{4}+0 \cdot 3 \mathrm{~V}_{2} \mathrm{O}_{5} \\
\Delta G^{\circ}(1)=0 \cdot 3\left[\Delta G^{\circ}\left(\mathrm{Li}_{2} \mathrm{O}\right)+\Delta G^{\circ}\left(\mathrm{V}_{2} \mathrm{O}_{4}\right)-\Delta G^{\circ}\left(\mathrm{V}_{2} \mathrm{O}_{5}\right)\right]\end{array}$ & $\begin{array}{l}\chi\left(\mathrm{V}_{2} \mathrm{O}_{5}\right)- \\
\chi\left(\mathrm{LiV}_{2} \mathrm{O}_{5}\right)\end{array}$ & $\Delta G^{\circ} / 0 \cdot 6 \mathrm{~F}$ & $\begin{array}{l}\text { Only } \mathrm{V}^{5+} \text { and } \mathrm{V}^{4+} \text { species } \\
\text { are present } \\
\chi\left(\mathrm{V}_{2} \mathrm{O}_{5}\right)>\chi\left(\mathrm{V}_{2} \mathrm{O}_{4}\right)\end{array}$ \\
\hline $\begin{array}{l}\mathrm{Li}_{0 \cdot 6} \mathrm{~V}_{2} \mathrm{O}_{4 \cdot 6} \rightarrow \mathrm{LiV}_{2} \mathrm{O}_{4 \cdot 6} \\
0 \cdot 4 \mathrm{Li}+\mathrm{Li}_{0 \cdot 6} \mathrm{~V}_{2} \mathrm{O}_{4 \cdot 6}\left(\equiv 0 \cdot 4 \mathrm{~V}_{2} \mathrm{O}_{4}+0 \cdot 6 \mathrm{LiV}_{2} \mathrm{O}_{5}\right) \rightarrow \\
0 \cdot 2 \mathrm{Li}_{2} \mathrm{O}+0 \cdot 2 \mathrm{~V}_{2} \mathrm{O}_{3}+0 \cdot 2 \mathrm{~V}_{2} \mathrm{O}_{4}+0 \cdot 3 \mathrm{Li}_{2} \mathrm{O}+ \\
0 \cdot 3 \mathrm{~V}_{2} \mathrm{O}_{4}+0 \cdot 3 \mathrm{~V}_{2} \mathrm{O}_{5} \equiv \mathrm{LiV}_{2} \mathrm{O}_{4 \cdot 6} \\
\Delta G^{\circ}(1)=0 \cdot 2\left[\Delta G^{\circ}\left(\mathrm{Li}_{2} \mathrm{O}\right)+\Delta G^{\circ}\left(\mathrm{V}_{2} \mathrm{O}_{3}\right)-\Delta G^{\circ}\left(\mathrm{V}_{2} \mathrm{O}_{4}\right)\right]\end{array}$ & $\begin{array}{l}\chi\left(\mathrm{V}_{2} \mathrm{O}_{4}\right)- \\
\chi\left(\mathrm{LiV}_{2} \mathrm{O}_{4}\right)\end{array}$ & $\Delta G^{\circ} / 0 \cdot 4 \mathrm{~F}$ & $\begin{array}{l}\text { All the three vanadium } \\
\text { species, } \mathrm{V}^{5+}, \mathrm{V}^{4+} \text { and } \\
\mathrm{V}^{3+} \text { appear } \\
\chi\left(\mathrm{V}_{2} \mathrm{O}_{4}\right)>\chi\left(\mathrm{LiV}_{2} \mathrm{O}_{5}\right)\end{array}$ \\
\hline $\begin{array}{l}\mathrm{Li}_{1 \cdot 0} \mathrm{~V}_{2} \mathrm{O}_{4 \cdot 6} \rightarrow \mathrm{Li}_{1 \cdot 6} \mathrm{~V}_{2} \mathrm{O}_{4 \cdot 6} \\
\left(\mathrm{Li}_{1 \cdot 0} \mathrm{~V}_{2} \mathrm{O}_{4 \cdot 6} \equiv 0 \cdot 4 \mathrm{~V}_{2} \mathrm{O}_{4}+0 \cdot 6 \mathrm{LiV}_{2} \mathrm{O}_{5}\right) \\
0 \cdot 6 \mathrm{Li}+0 \cdot 6 \mathrm{LiV}_{2} \mathrm{O}_{5} \rightarrow 0 \cdot 6 \mathrm{Li}_{2} \mathrm{~V}_{2} \mathrm{O}_{5} \equiv 0 \cdot 6\left(\mathrm{Li}_{2} \mathrm{O}+\mathrm{V}_{2} \mathrm{O}_{4}\right) \\
\Delta G^{\circ}(1)=0 \cdot 6\left[\Delta G^{\circ}\left(\mathrm{Li}_{2} \mathrm{O}\right)+\Delta G^{\circ}\left(\mathrm{V}_{2} \mathrm{O}_{4}\right)-\Delta G^{\circ}\left(\mathrm{V}_{2} \mathrm{O}_{5}\right)\right]\end{array}$ & $\begin{array}{l}\chi\left(\mathrm{LiV}_{2} \mathrm{O}_{5}\right)- \\
\chi\left(\mathrm{Li}_{2} \mathrm{~V}_{2} \mathrm{O}_{5}\right)\end{array}$ & $\Delta G^{\circ} / 1 \cdot 2 \mathrm{~F}$ & $\begin{array}{l}\mathrm{V}^{4+} \text { and } \mathrm{V}^{3+} \text { are present } \\
\chi\left(\mathrm{LiV}_{2} \mathrm{O}_{5}\right)>\chi\left(\mathrm{Li}_{2} \mathrm{~V}_{2} \mathrm{O}_{4}\right)\end{array}$ \\
\hline $\begin{array}{l}\mathrm{Li}_{1 \cdot 6} \mathrm{~V}_{2} \mathrm{O}_{4 \cdot 6} \rightarrow \mathrm{Li}_{2 \cdot 0} \mathrm{~V}_{2} \mathrm{O}_{4 \cdot 6} \\
\left(\mathrm{Li}_{1 \cdot 6} \mathrm{~V}_{2} \mathrm{O}_{4 \cdot 6} \equiv 0 \cdot 6 \mathrm{Li}_{2 \cdot 0} \mathrm{~V}_{2} \mathrm{O}_{5}+0 \cdot 4 \mathrm{LiV}_{2} \mathrm{O}_{4}\right) \\
0 \cdot 4 \mathrm{Li}+0 \cdot 4 \mathrm{LiV}_{2} \mathrm{O}_{4} \rightarrow 0 \cdot 4 \mathrm{Li}_{2} \mathrm{~V}_{2} \mathrm{O}_{4} \equiv 0 \cdot 4 \mathrm{Li}_{2} \mathrm{O}+0 \cdot 4 \mathrm{~V}_{2} \mathrm{O}_{3} \\
\Delta G^{\circ}(1)=0 \cdot 4\left[\Delta G^{\circ}\left(\mathrm{Li}_{2} \mathrm{O}\right)+\Delta G^{\circ}\left(\mathrm{V}_{2} \mathrm{O}_{3}\right)-\Delta G^{\circ}\left(\mathrm{V}_{2} \mathrm{O}_{4}\right)\right]\end{array}$ & $\begin{array}{c}\chi\left(\mathrm{LiV}_{2} \mathrm{O}_{4}\right)- \\
\chi\left(\mathrm{Li}_{2} \mathrm{~V}_{2} \mathrm{O}_{4}\right)\end{array}$ & $\Delta G^{\circ} / 0 \cdot 8 \mathrm{~F}$ & $\begin{array}{l}\mathrm{V}^{4+} \text { and } \mathrm{V}^{3+} \text { are present } \\
\chi\left(\mathrm{LiV}_{2} \mathrm{O}_{4}\right)>\chi\left(\mathrm{Li}_{2} \mathrm{~V}_{2} \mathrm{O}_{5}\right)\end{array}$ \\
\hline $\begin{array}{l}\mathrm{Li}_{2 \cdot 0} \mathrm{~V}_{2} \mathrm{O}_{4 \cdot 6} \rightarrow \mathrm{Li}_{2 \cdot 6} \mathrm{~V}_{2} \mathrm{O}_{4 \cdot 6} \\
\left(\mathrm{Li}_{2 \cdot 0} \mathrm{~V}_{2} \mathrm{O}_{4 \cdot 6} \equiv 0 \cdot 4 \mathrm{Li}_{2} \mathrm{~V}_{2} \mathrm{O}_{4}+0 \cdot 6 \mathrm{Li}_{2} \mathrm{~V}_{2} \mathrm{O}_{5}\right) \\
0 \cdot 6 \mathrm{Li}+0 \cdot 6 \mathrm{Li}_{2} \mathrm{~V}_{2} \mathrm{O}_{5} \rightarrow 0 \cdot 6 \mathrm{Li}_{3} \mathrm{~V}_{2} \mathrm{O}_{5} \equiv 0 \cdot 6 / 2\left(3 \mathrm{Li}_{2} \mathrm{O}+\right. \\
\left.\mathrm{V}_{2} \mathrm{O}_{3}+\mathrm{V}_{2} \mathrm{O}_{4}\right) \\
\Delta G^{\circ}(1)=0 \cdot 3\left[\Delta G^{\circ}\left(\mathrm{Li}_{2} \mathrm{O}\right)+\Delta G^{\circ}\left(\mathrm{V}_{2} \mathrm{O}_{3}\right)+\right. \\
\Delta G^{\circ}\left(\mathrm{V}_{2} \mathrm{O}_{4}\right)-2 \Delta G^{\circ}\left(\mathrm{V}_{2} \mathrm{O}_{5}\right)\end{array}$ & $\begin{array}{c}\chi\left(\mathrm{Li}_{2} \mathrm{~V}_{2} \mathrm{O}_{5}\right)- \\
\chi\left(\mathrm{Li}_{3} \mathrm{~V}_{2} \mathrm{O}_{5}\right)\end{array}$ & $\Delta G^{\circ} / 1.8 \mathrm{~F}$ & $\begin{array}{l}\mathrm{V}^{4+} \text { and } \mathrm{V}^{3+} \text { are present } \\
\chi\left(\mathrm{Li}_{2} \mathrm{~V}_{2} \mathrm{O}_{4}\right)>\chi\left(\mathrm{Li}_{3} \mathrm{~V}_{2} \mathrm{O}_{5}\right)\end{array}$ \\
\hline
\end{tabular}

Table 5. Electrochemical parameters of amorphous films.

\begin{tabular}{lcccccc}
\hline $\begin{array}{l}\text { Intercalated } \\
\mathrm{Li} \text { (in moles) }\end{array}$ & $\begin{array}{c}\text { Formula of } \\
\text { intercalated material }\end{array}$ & $\begin{array}{c}\text { Calculated } \\
-\Delta G^{\circ}(\mathrm{kJ})\end{array}$ & $\begin{array}{c}\text { Calculated } \\
\text { voltage }(\mathrm{V})\end{array}$ & $\begin{array}{c}\text { Observed voltage } \\
\text { 1st discharge }(\mathrm{V})\end{array}$ & $\begin{array}{c}\text { Observed voltage } \\
\text { 1st charge }(\mathrm{V})\end{array}$ & $\begin{array}{c}\text { Vanadium oxidation } \\
\text { states in the films }\end{array}$ \\
\hline $0 \cdot 6$ & $\mathrm{Li}_{0 \cdot 6} \mathrm{~V}_{2} \mathrm{O}_{4 \cdot 6}$ & $187 \cdot 5$ & $3 \cdot 24$ & $2 \cdot 40$ & $3 \cdot 3$ & $\mathrm{~V}^{5+}$ and $\mathrm{V}^{4+}$ \\
1.0 & $\mathrm{LiV}_{2} \mathrm{O}_{4 \cdot 6}$ & 113.8 & 2.95 & $2 \cdot 25$ & $2 \cdot 8$ & $\mathrm{~V}^{5+}, \mathrm{V}^{4+}$ and $\mathrm{V}^{3+}$ \\
1.6 & $\mathrm{Li}_{1 \cdot 6} \mathrm{~V}_{2} \mathrm{O}_{4 \cdot 6}$ & $300 \cdot 2$ & $2 \cdot 59$ & $1 \cdot 8$ & $2 \cdot 25$ & $\mathrm{~V}^{4+}$ and $\mathrm{V}^{3+}$ \\
$2 \cdot 0$ & $\mathrm{Li}_{2 \cdot 0} \mathrm{~V}_{2} \mathrm{O}_{4 \cdot 6}$ & $168 \cdot 8$ & $2 \cdot 18$ & 1.6 & $1 \cdot 85$ & $\mathrm{~V}^{4+}$ and $\mathrm{V}^{3+}$ \\
$2 \cdot 6$ & $\mathrm{Li}_{2 \cdot 6} \mathrm{~V}_{2} \mathrm{O}_{4 \cdot 6}$ & $403 \cdot 0$ & $2 \cdot 32$ & - & - & $\mathrm{V}^{4+}$ and $\mathrm{V}^{3+}$ \\
\hline
\end{tabular}

tinuously as seen in figure 1 . Therefore, the value of $x$ in $\mathrm{Li}_{x} \mathrm{~V}_{2} \mathrm{O}_{5}$ when intercalation begins to occur into both $\mathrm{V}_{2} \mathrm{O}_{5}$ and $\mathrm{V}_{2} \mathrm{O}_{4}$ regions can be calculated. Simultaneous intercalation occurs when $\chi_{\mathrm{Li}_{x} \mathrm{~V}_{2} \mathrm{O}_{4}}=\chi_{\mathrm{Li}_{y} \mathrm{~V}_{2} \mathrm{O}_{5}}$.

Using the definition of $\chi$ and the values of electronegativities given in table 1 one can show that $y=0 \cdot 828 x-$ $0 \cdot 205$ which means that $y$ assumes positive values only when $x=0 \cdot 205 / 0 \cdot 828=0 \cdot 25$. Therefore, simultaneous intercalation into both regions occurs when $\mathrm{Li}_{x} \mathrm{~V}_{2} \mathrm{O}_{5}$ $(x=0 \cdot 25)$ has formed. $x=0 \cdot 25$ also marks the beginning of the formation of $\mathrm{V}^{3+}$ by reduction of $\mathrm{V}^{4+}$ even as $\mathrm{V}^{5+}$ is present in the film from the remaining $\mathrm{V}_{2} \mathrm{O}_{5}$. The observations in figure 2 are thus well understood. It is also our suspicion that in the amorphous matrix, $\Delta G^{\circ}(2)$ term which is equal to $k \Delta \chi^{2}$ may be determined by a much lower value of $k$ instead of $700 \mathrm{~kJ} / \mathrm{mole}$ (it may be half this value, because the $\mathrm{Li}_{2} \mathrm{O}$ mixing term involved in $\Delta G^{\circ}(2)$ is already partly achieved in the amorphous films due to its inherent entropy). Thus, the $\Delta G$ values used in our calculations are somewhat higher than the observed voltages for amorphous films (table 4).

In crystalline films, where no $\mathrm{V}^{4+}$ is detected to start with in the XPS studies, we do not expect appearance of $\mathrm{V}^{3+}$ when $\mathrm{V}^{5+}$ is still present. But in films obtained by sputtering at high sputtering gas pressures there is reduction of $\mathrm{V}^{5+}$ to $\mathrm{V}^{4+}$ as noted earlier because of the local heating to high temperatures which leads to decomposition of $\mathrm{V}_{2} \mathrm{O}_{5}$ to $\mathrm{V}_{2} \mathrm{O}_{4}$ and $\mathrm{O}_{2}$. In such films, one should expect appearance of $\mathrm{V}^{3+}$ when $\mathrm{V}^{5+}$ is still present. This has indeed been observed in the present crystalline films (figure $2 \mathrm{a}$ ). 


\subsection{Sequestration of lithium ions}

Another important observation in the electrochemical studies of the thin films is the irrecoverable part of the intercalated lithium. This lithium is sequestrated in the structures of both crystalline and amorphous films. The magnitude of sequestration is higher in amorphous films than in crystalline films and occurs in the first cycle itself. We feel that sequestration represents a process of structural stabilization of the film and is irreversible, i.e. the $\Delta G$ made available during intercalation reaction is partly internally used for non-electrochemical work of structural stabilization and thereby reducing the magnitude of $\Delta G$ available for electrochemical work.

This is well supported by the observed low voltage of amorphous films compared to calculated values where it is reasonable to expect the process of stabilization to occur. Perhaps for the same reason the initial measured capacities are very high indicating a high value of total charge as a result of intercalation which is not repeated in the subsequent cycles. The exact nature of this stabilization is unclear at this time, but it is most likely the stabilization of the interfaces between $\mathrm{V}_{2} \mathrm{O}_{4}$ and $\mathrm{V}_{2} \mathrm{O}_{5}$ nanoregions. We noted earlier that $\mathrm{V}_{2} \mathrm{O}_{4}$ regions are constituted either from rutile like, 3-edge sharing, octahedral units or from simply distorted (along one axis) and four edge sharing octahedral units. These units have to establish registry at the interface with $\mathrm{V}_{2} \mathrm{O}_{5}$ regions which are constituted with square pyramids. It is intuitively clear that such interfaces are strained. Lithium ions which enter this region are structurally "locked up" and part of the chemical energy released from the intercalation process is used up in bringing about the needed structural rearrangement at the interfaces.

In crystalline films also, we have noted sequestration of $\mathrm{Li}^{+}$ions but to a lower extent. This is evidently associated with large surfaces of the nanorods of $\mathrm{V}_{2} \mathrm{O}_{5}$ as evident in the scanning electron micrographs. These rods are progressively "electrochemically sintered" by the sequestrated $\mathrm{Li}^{+}$ions. Since the rods are much bigger than $\mathrm{V}_{2} \mathrm{O}_{4}$ and $\mathrm{V}_{2} \mathrm{O}_{5}$ nanoregions of the amorphous films, the surface areas involved are also lower in crystalline films consistent with the lower degree of sequestration. Therefore, in second and subsequent electrochemical cycles chemical energy is almost entirely available for electrical work and the true equivalence of the electrochemical potential and free energy release is observed. Both the amorphous and crystalline (now fully electrochemically and perhaps even structurally amorphized) films show a larger range of reversible potentials. Some degree capacitance fading is observed in crystalline films even in subsequent galvanostatic cycles. This may be attributed to the gradual disappearance of rod like morphology by the electrochemically induced sintering. The process is actually surface modification by sequestrated lithium ions which act to "zip up" the different rods at their points of contact. Since this process continues through several cycles we expect a gradual-not abrupt-disappearance of both capacitance fading and sequestration. It is for this reason that amorphous films appear to be more cyclable at constant capacities.

\subsection{Electrochemical cycling and the structure of films}

The electrochemical cycling has highly deleterious effect on the structure. This is because as $x$ increases from 0 to 3 , vanadium is reduced from +5 to +3 state and the $\mathrm{V}-\mathrm{O}$ bonding in $\left[\mathrm{VO}_{5}\right]$ and $\left[\mathrm{VO}_{4}\right]$ units increases in ionicity. There is, therefore, a tendency towards octahedralization of the oxygen surroundings of $\mathrm{V}^{n+}$ and also an increase of the $\mathrm{V}-\mathrm{O}$ distances. Since the changes occur to various degrees in $\left[\mathrm{VO}_{n}\right]$ polyhedra throughout the structure, structural order becomes difficult to maintain and the films become amorphous. We may note here that in the structure of the crystalline films. $\mathrm{V}^{4+}$ in $\left[\mathrm{VO}_{5 / 2}\right]^{-}$and $\mathrm{V}^{3+}$ $\left[\mathrm{VO}_{5 / 2}\right]^{2-}$ units have more oxygens around them than what is available to them in crystalline $\mathrm{V}_{2} \mathrm{O}_{4}$ or $\mathrm{V}_{2} \mathrm{O}_{3}$. Thus in $\mathrm{V}_{2} \mathrm{O}_{4}$ there is a finite tendency to return to $\mathrm{V}_{2} \mathrm{O}_{5}$ structure. That is if there are driving forces like for example, requirement to mitigate the structural strains around $\left[\mathrm{VO}_{5}\right]^{-}$, it would tend to form $\left[\mathrm{VO}_{5 / 2}\right]^{0}$ through a disproportionation reaction

$$
2\left[\mathrm{VO}_{5 / 2}\right]^{-} \leftrightarrow\left[\mathrm{VO}_{5 / 2}\right]^{0}+\left[\mathrm{VO}_{5 / 2}\right]^{2-} ; 2 \mathrm{~V}^{4+} \leftrightarrow \mathrm{V}^{5+}+\mathrm{V}^{3+} .
$$

This is supported by the observation that even in bulk $\mathrm{Li}_{x} \mathrm{~V}_{2} \mathrm{O}_{5}, \mathrm{~V}^{5+}$ coexist in composition with $x>1.5$ where only $\mathrm{V}^{4+}$ and $\mathrm{V}^{3+}$ are expected to be present. Formation of $\left[\mathrm{VO}_{5}\right]^{2-}$ (i.e. $\mathrm{V}^{3+}$ ) provides significant ionicity of bonding which assists reorganization of the polyhedron. Therefore, presence of $\mathrm{V}^{5+}$ together with $\mathrm{V}^{4+}$ and $\mathrm{V}^{3+}$ in $\mathrm{Li}_{x} \mathrm{~V}_{2} \mathrm{O}_{5}$ films for $x>1.5$ is reasonable. It is unlikely that $\mathrm{V}^{3+}$ formation is associated with $\mathrm{V}^{4+}$ formation $\left(\mathrm{V}_{2} \mathrm{O}_{4}\right)$ via oxygen loss. It may also be noted that for $\mathrm{O} / \mathrm{V}$ ratio of $2 \cdot 5\left[\mathrm{~V}^{3+} \mathrm{O}_{5}\right]^{2-}$ structures tend to collapse and reorganize as noted by Zavalij and Whittingham (1999).

Another important observation supportive of the above arguments is gradual increase in the retention of $\mathrm{V}^{4+}$ in electrochemically cycled $\mathrm{V}_{2} \mathrm{O}_{5}$ ("crystalline") films. This is to be expected because, sequestered $\mathrm{Li}^{+}$retains $\mathrm{V}^{4+}$ as $\left(\mathrm{Li}^{+}, \mathrm{V}^{4+}\right)$ in place of the original $\mathrm{V}^{5+}$ to maintain electrical neutrality. Since $\mathrm{Li}^{+}$retention-sequestered $\mathrm{Li}^{+}$-increases so does the $\mathrm{V}^{4+}$ in these films.

\subsection{Effect of lithiation on $\mathrm{V}_{2} \mathrm{O}_{5}$ band structure-a molecular orbital approach}

$\mathrm{V}_{2} \mathrm{O}_{5}$ and its lithiation has attracted much attention in literature due to their interesting magnetic and electrical properties. While $\mathrm{V}^{5+}$ is a $d^{0}$ ion, $\mathrm{V}^{4+}$ and $\mathrm{V}^{3+}$ are $d^{1}$ and $d^{2}$ ions, respectively. We concern ourselves here only with electrical property changes expected as a result of lithiation of $\mathrm{V}_{2} \mathrm{O}_{5}$ films. First of all the crystalline $\mathrm{V}_{2} \mathrm{O}_{5}$ structure 
is made up of $s p$ units of $\left[\mathrm{VOO}_{1 / 2} \mathrm{O}_{3 / 3}\right]$, (for convenience written as $\left[\mathrm{VO}_{5 / 2}\right]^{0}$ units) forming sheets of [uudd] type (Zavalij and Whittingham 1999). Whereas the valency of vanadium changes during lithiation from 5 to 3 , the loss of positive charge is made up by $\mathrm{Li}^{+}$ions which locate themselves in the interlamellar region (between [uudd] sheets). XRD investigation of films, intercalated with lithium (in the first cycle) has revealed only a modest increase in $c$ parameter of the oriented (along $\langle 001\rangle$ ) film structure. Therefore, it is reasonable to assume that during intercalation the topology of $\left[\mathrm{VO}_{5 / 2}\right]$ units remains virtually unchanged. The only change is the state of charge, $\left[\mathrm{VO}_{5 / 2}\right]^{0} \rightarrow\left[\mathrm{VO}_{5 / 2}\right]^{-} \rightarrow\left[\mathrm{VO}_{5 / 2}\right]^{2-}$. The first $\mathrm{Li}^{+}$ion introduced into the interlayer region tries to create for itself an octahedral oxygen environment. This disturbs slightly the oxygen positions; the apical oxygen of $\left[\mathrm{VOO}_{1 / 2} \mathrm{O}_{3 / 3}\right]$ is shifted towards one of the $\mathrm{O}-\mathrm{O}$ edges of the layer of [VOO $\left.\mathrm{VOO}_{1 / 2} \mathrm{O}_{3 / 2}\right]$ square pyramids just above it. In fact, in bulk $\mathrm{V}_{2} \mathrm{O}_{5}$ studies, [uudd] layer is shown to become $[u d u d]$ in the process. The slight loss in the alignment of apical oxygens of the layers in the $s p$ structure changes over to (distorted) trigonal bipyramid $(t b p)$. With further incorporation of $\mathrm{Li}^{+}$ions, $t b p$ changes over to octahedron, albeit again distorted. Therefore, we assume that there is an evolution of the oxygen polyhedron around vanadium ion from $s p \rightarrow t b p \rightarrow \mathrm{O}$. This parallels the increase in the ionicity of $\mathrm{V}-\mathrm{O}$ bonding and reduction of $\mathrm{V}^{5+} \rightarrow \mathrm{V}^{4+} \rightarrow \mathrm{V}^{3+}$. Several theoretical investigations (Carathers et al 1973; Bullet 1980; Mattheis 1994; Eyert and Hock 1998; Kurmaer et al 1998; Ven et al 1998; Hermann et al 2001; Herbert et al 2002) have addressed the problem of the resulting electronic band structures both in $\mathrm{V}_{2} \mathrm{O}_{5}$ and in other vanadium oxides. Density functional approach has been particularly heavily employed (Eyert and Hock 1998; Hermann et al 2001). But our focus here is to obtain a qualitative understanding of the band structure alterations resulting from lithiation of $\mathrm{V}_{2} \mathrm{O}_{5}$ and $\mathrm{V}_{2} \mathrm{O}_{4 \cdot 6}$ films based on molecular orbital (MO) approach. Only the valence orbitals, $3 d, 4 s$ and $4 p$ of vanadium and the $2 s, 2 p$ orbitals of oxygen are assumed to participate in the MOs. We note that there are atleast 3 crystallographically distinguishable oxygens in the structure. First there are apical oxygens of the vanadyl groups which are in double bonded state $(\mathrm{V}=\mathrm{O})$, clearly identified in Raman and infrared spectroscopies (Gies et al 2005) $\left(981 \mathrm{~cm}^{-1}, \mathrm{~V}=\mathrm{O}\right.$ stretching mode and $401 \mathrm{~cm}^{-1}$ bending modes in Raman spectra). There are bridging oxygen connecting double stranded $\left[\mathrm{VO}_{5}\right]$ strips. And, there are oxygens which are three coordinated to vanadium atoms and present in the edges of the $s p$ units. We further assume that relevant symmetry adopted linear combination (SALC) of the oxygen valence orbitals can be made for the required symmetries. Since all the MOs and also the nonbonding orbitals on oxygen get filled in all situations (figure 3), this assumption does not affect the discussion. The atomic orbitals of the central vanadium atom participating in bonding in the three symmetries are crucial and are given in table 6. The MO diagrams for the three symmetries of $\left[\mathrm{VO}_{5}\right]$ polyhedron are shown in table 5 and figure 3 together. The expected band energy diagram for the three symmetries are also shown in the same figure. For the sake of clarity oxygen orbitals are placed together since it is not going to affect the important features we wish to emphasize.

The vanadium oxygen bond is about $55 \%$ ionic on the scale of Pauling electronegativities. Therefore, in figure 3 oxygen orbitals are shown at lower energy levels. Each vanadium atom has a share of 2.5 oxygen atoms or $2.5 \times 4=10$ oxygen orbitals available for bonding. Of these 2.5 orbitals on an average are $s$ orbitals and 7.5 are $p$ orbitals. They carry a total of 15 electrons $\left(s^{2} p^{4} \times 2 \cdot 5\right)$ available in them. Thus in the case of $s p$ and $t b p$ geometries, 5 electrons are used in forming bonds with vanadium and the remaining 5 orbitals remain non-bonding. In the process of filling the resulting molecular orbitals with electrons all these orbitals are filled up. Thus the nonbonding oxygen orbitals evolve into filled valence band (right side in the figure). The five electrons of vanadium and 5 electrons from oxygens together fill bonding orbitals and remaining 10 electrons of the oxygen atoms fill the non-bonding orbitals. It is to be noted that in $\mathrm{O}_{h}$ symmetry also, the available oxygen per vanadium remains only 2.5. Therefore, the number of orbitals and electrons of oxygen used in bonding are six each while the nonbonding orbitals of oxygen which evolve into the valence band has only 4 orbitals. The electrons available in $\mathrm{V}_{2} \mathrm{O}_{5}$ fill up to the top of this valence band. The bands have been schematically represented so as to reflect the number of orbitals involved in its formation.

The point of interest in this diagram is the non-bonding $d$ orbitals on vanadium. As the symmetry changes from $s p \rightarrow t b p \rightarrow \mathrm{O}_{h}$, the number of $d$ orbitals of non-bonding category increases from 1 to 3 . These orbitals evolve into narrow to mid size bands as the symmetry evolves. And this $d$ band constitutes the conduction band for lithiated $\mathrm{V}_{2} \mathrm{O}_{5}$. In the absence of lithiation, experiments show that in $s p$ structured $\mathrm{V}_{2} \mathrm{O}_{5}$ there is a gap between the narrow (one orbital) $d$ band and the top of the valence band. If the symmetry does not change at low level of lithiation as in $\mathrm{Li}_{0.04} \mathrm{~V}_{2} \mathrm{O}_{5}$, we expect population in this band. Since the empty $d_{x z}$ orbitals on neighbouring vanadiums do not overlap sufficiently in $s p$ units, the electron resides on a chosen $d$ orbital and exhibits only hopping conduction. But as $x$ in $\mathrm{Li}_{x} \mathrm{~V}_{2} \mathrm{O}_{5}$ increases and the geometry becomes $t b p$, this band expands (doubles in the number of states available). The $d$ orbitals may overlap and the material may behave like a conductor. The gap between the top of non-bonding oxygen band and the $d$-band may close up, but its role is irrelevant as the Fermi level now lies in the $d$-band itself. For values of $x$ such that $2 \leq x \leq 3$, it has to be metallic as indicated in the band diagram and indeed as noted in the introduction as unpublished observation. 

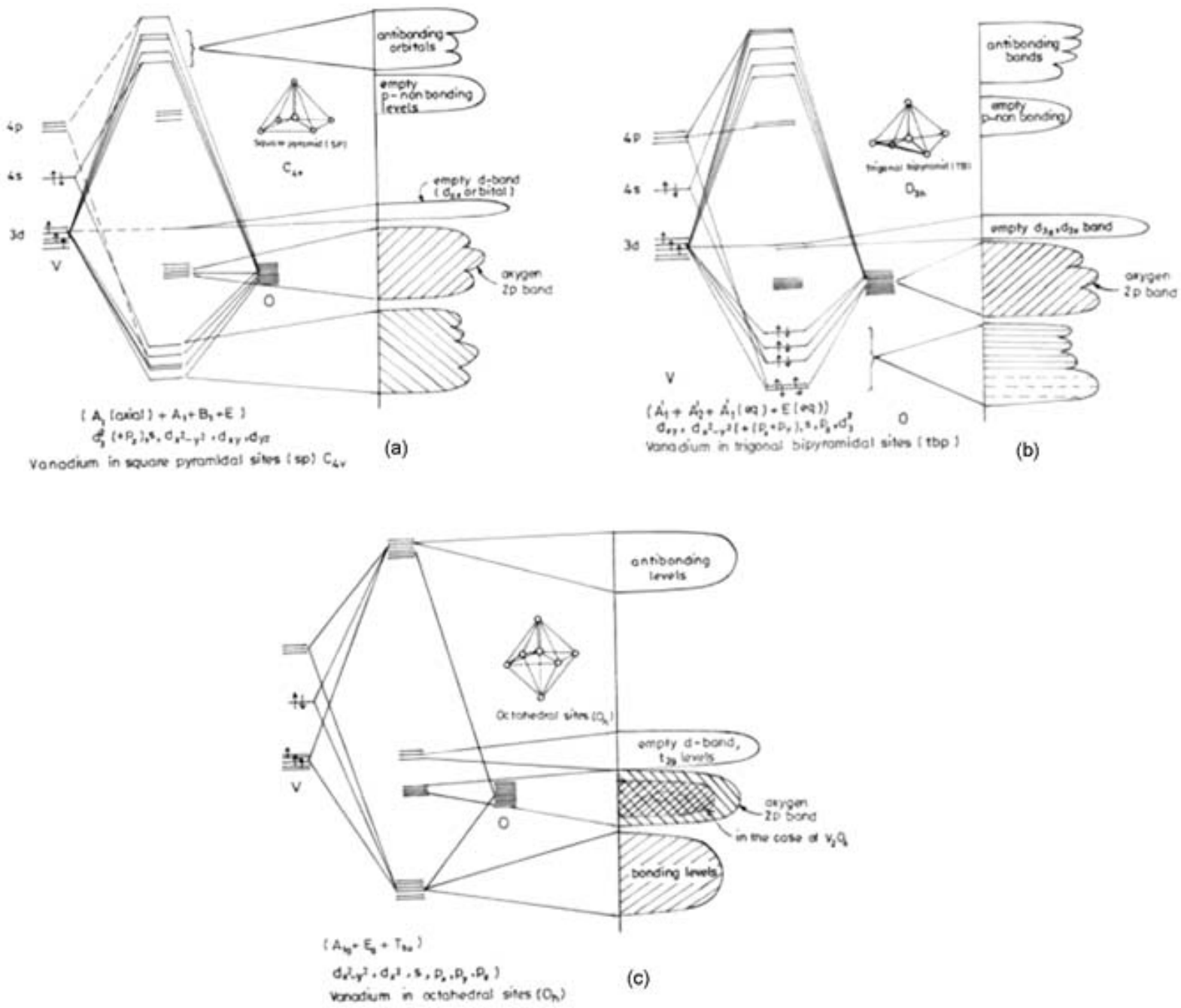

Figure 3. $\mathrm{MO}$ based energy band structure of $\mathrm{V}_{2} \mathrm{O}_{5}$ in three symmetries in which $\mathrm{V}$ is found: $\mathrm{C}_{4 v}(\mathbf{a}), \mathrm{D}_{3 h}(\mathbf{b})$ and $\mathrm{O}_{h}(\mathbf{c})$, during lithiation and formation of $\mathrm{Li}_{x} \mathrm{~V}_{2} \mathrm{O}_{5}(0<x<3)$. In (c) the band corresponding to non-bonding oxygen levels are inscribed with a smaller hatched band. This refers to $\mathrm{V}_{2} \mathrm{O}_{4}$ in the same structure.

Note: Similar diagram is applicable to $\mathrm{V}_{2} \mathrm{O}_{4}$ also with vanadium in $\mathrm{O}_{h}$ symmetry except that the lone pair band is only half of that in $\mathrm{V}_{2} \mathrm{O}_{5}$ : oxygen contributes to $4 \times 2$ orbitals and 12 electrons and $\mathrm{V}$ gives 5 electrons. Total of 17 electrons occupy 6 bonding and 2 non-bonding levels fully. One electron will be in the $d$ band giving rise to metallic conduction; or at low temperature to an antiferromagnetic insulator (spins on adjacent sites are paired and the symmetry is broken due to Peierl's transition).

Table 6. Participating orbitals and the symmetry designations of resulting MOs.

\begin{tabular}{lcccc}
\hline $\begin{array}{l}\text { Geometry of } \\
{\left[\mathrm{VO}_{5}\right] \text { units }}\end{array}$ & $\begin{array}{c}\text { Point } \\
\text { group }\end{array}$ & $\begin{array}{c}\text { Molecular orbital } \\
\text { symmetry (species) }\end{array}$ & $\begin{array}{c}\text { Participating } \\
\text { vanadium orbitals }\end{array}$ & $\begin{array}{c}\text { Participating } \\
\text { oxygen orbitals }\end{array}$ \\
\hline $\begin{array}{l}\text { Square pyramid }(s p) \\
\text { Trigonal bipyramid }(t b p)\end{array}$ & $\mathrm{C}_{4 v}$ & $A_{1}$ (axial) $+A_{1}$ (equatorial) $+B_{1}+E$ & $d z^{2}($ also $p z), s, d x^{2}-y^{2}, d x y, d y z$ & $2 s$ and $2 p$ \\
Octahedron $(\mathrm{O})$ & $\mathrm{D}_{3 h}$ & $A_{1}^{\prime}$ (axial) $+A_{1}^{\prime}$ (equatorial) $+A_{2}^{\prime}+E$ & $d x y, d x^{2}-y^{2}($ also $p x, p y), s, p z, d z^{2}$ & $2 s$ and $2 p$ \\
& $\mathrm{O}_{h}$ & $A_{1 g}+E_{g}+T_{1 u}$ & $d x^{2}-y^{2}, d_{z}^{2}, s, p x, p y$ and $p z$ & $2 s$ and $2 p$ \\
\hline
\end{tabular}

In the case of nonstoichiometric amorphous films, we should expect band energy diagram of $\mathrm{V}_{2} \mathrm{O}_{5}$ to coexist with those relevant for $\mathrm{V}_{2} \mathrm{O}_{4} . \mathrm{V}_{2} \mathrm{O}_{4}$ band diagram can be considered as similar to $\mathrm{V}_{2} \mathrm{O}_{5}$ in $\mathrm{O}_{h}$ symmetry except that oxygen non-bonding band to be smaller by 50 percent as it is constituted from only two non-bonding oxygen orbitals. The $t_{2 g}$ band of $\mathrm{V}_{2} \mathrm{O}_{4}$ is already populated with vanadium electrons. This constitutes a metallic state for the nano 
$\mathrm{V}_{2} \mathrm{O}_{4}$ regions except that the disorder inherent to glassy state localizes the tail states where electrons reside. However, with increased lithiation not only the extended states get occupied, but the $\mathrm{V}_{2} \mathrm{O}_{5}$ regions also become conducting. The composition being $60 \% \mathrm{~V}_{2} \mathrm{O}_{5}$ it leads to a percolation of conducting regions. The Fermi levels in $\mathrm{V}_{2} \mathrm{O}_{5}$ and $\mathrm{V}_{2} \mathrm{O}_{4}$ regions are unlikely to be different as they originate from the non-bonding $d$-orbitals of vanadium and not much electronic band bending may occur at the interfaces.

\subsection{Oxygen-1s XPS spectra and the model}

One residual question in this investigation is about the XPS characterization of oxygen $1 s$ levels. As noted earlier the oxygen levels are fully occupied in all compositions. Thus the $\mathrm{O}-1 s$ levels of all oxygens are essentially screened to the same extent by the $2 s, 2 p$ electrons which penetrate the $1 s$ orbitals. We may still expect some difference between the oxygens in $\mathrm{V}_{2} \mathrm{O}_{3}$-like, $\mathrm{V}_{2} \mathrm{O}_{4}$-like and $\mathrm{V}_{2} \mathrm{O}_{5}$-like regions due to different degrees of polarization by the bonding to vanadium in various valence states. When $\mathrm{Li}^{+}$ions are sequestered, they also polarize the electron cloud to a non-negligible extent. The oxygen $1 s$ spectra seem to be consistent with this picture. In the XPS of amorphous films (figure 3), there are two oxygen peaks whereas there is only one peak present in the XPS spectrum of $\mathrm{V}_{2} \mathrm{O}_{5}$ crystalline films. However, after $\mathrm{Li}^{+}$intercalation two peaks develop in $\mathrm{Li}_{x} \mathrm{~V}_{2} \mathrm{O}_{5}$ films also. In both $\mathrm{V}_{2} \mathrm{O}_{4.6}$ and $\mathrm{V}_{2} \mathrm{O}_{5}$ films a third peak corresponding to oxygen bonded to $\mathrm{V}^{3+}$ develops at high degrees of lithiation. And, as expected, crystalline $\mathrm{V}_{2} \mathrm{O}_{5}$ film after the first electrochemical cycling itself begins to retain the second oxygen $1 s$ peak due to the retention of $\mathrm{V}^{4+}$ which is coupled to sequestered $\mathrm{Li}^{+}$ions.

\section{Conclusions}

The entire range of observations made in the investigation of stoichiometric $\left(\mathrm{V}_{2} \mathrm{O}_{5}\right)$ and nonstoichiometric $\left(\mathrm{V}_{2} \mathrm{O}_{4 \cdot 6}\right)$ vanadium oxide films seem to be understood by making use of the above structural model. It is postulated that the nonstoichiometric films are constituted of nanoregions of $\mathrm{V}_{2} \mathrm{O}_{5}$ and $\mathrm{V}_{2} \mathrm{O}_{4}$ and that the structure of $\mathrm{V}_{2} \mathrm{O}_{5}$ evolves as a function of lithiation from $s p \rightarrow t b p \rightarrow \mathrm{O}$ symmetries. The observed sequestration of $\mathrm{Li}^{+}$ions is attributed to lithiation of interface sites which results in the stabilization of the structures of the films. The voltages observed in galvanostatic studies can be estimated using thermodynamic data along with corrections based on a heuristic electronegativity based estimates of energy changes. The nanotexture of the amorphous films account for the observed coexistence of $\mathrm{V}^{3+}$ and $\mathrm{V}^{5+}$ during lithiation. An MO based band energy diagram is proposed which explains the evolution of metallic conduction in lithiated $\mathrm{V}_{2} \mathrm{O}_{5}$.

\section{Acknowledgement}

One of the authors (KJR) acknowledges financial support from CNRS (France) and EGIDE (France).

\section{References}

Bullet D W 1980 J. Phys. C13 L595

Carathers E, Kleinmann L and Zang H I 1973 Phys. Rev. B7 3753

Chandrappa G T, Steunou N and Livage J 2002 Nature 416702

Clark R J H 1968 The chemistry of the vanadium and the titanium (New York)

Cocciantelli J M, Menetrier M, Delmas C, Doumerc J P, Pouchard M and Hagenmuller P 1992 Solid State Ionics 5099

Delmas C, Brethes S and Menetrier M 1991 J. Power Sources 34113

Delmas C, Cognac-Auradou H, Cocciantelli J M, Menetrier M and Doumerc J P 1994 Solid State Ionics 69257

Enjalbert R and Galy J 1986 Acta Crystallogr. C, Cryst. Struct. Commun. 111467

Eyert V and Hock K H 1998 Phys. Rev. B57 12727

Galy J, Darriet J and Hagenmuller P 1971 Rev. Chim. Min. 8509

Gies A, Pecquenard B, Benayad A, Martinez H, Gonbeau D, Fuess H and Levasseur A 2005 Solid State Ionics 1761627

Herbert C, Willinger M, Su D S, Pongratz P, Schattchneider P and Schologl R 2002 Eur. Phys. J. B28 407

Hermann K, Chakrabarti A, Haras A, Witko M and Tepper B 2001 Phys. Status Solidi (a) $\mathbf{1 8 7} 137$

JANAF Thermodynamic Tables 1998 ACS, APS and NIST: New York, 11th Edition

Kurmaer E Z et al 1998 J. Phys. Cond. Matter 104081

Mattheiss L F 1994 J. Phys. Cond. Matter 66477

Muhr H J, Krumeich F, Schönholzer U P, Bieri F, Niederberger M, Ganckler L J and Nesper R 2000 Adv. Mater. 12231

Müller U 1993 Inorganic structural chemistry (New York)

Pereira-Ramos J P, Messina R, Znaidi L and Baffier N 1988 Solid State Ionics 1886

Rocquefelte X, Boucher F, Gressier P and Ouvrard G 2003 Chem. Mater. 151812

Sanderson R T 1976 Chemical bonds and bond energy (New York: Academic Press)

Sanderson R T 1983 Polar covalence (New York: Academic Press)

Schwingenschlogl U, Eyert V and Eckern U 2003 Europhys. Lett. 64682

Ven A V D, Aydinol M K, Ceder G, Kresse G and Hofner J 1998 Phys. Rev. B58 2975

Wang Y W, Xu H Y, Wang H, Zhang Y C, Song Z Q, Yan H and Wan C R 2004 Solid State Ionics 167419

Wells A F 1995 Structural inorganic chemistry (New York)

West K, Zachau-Christiansen B, Jacobsen T and Skaarup S 1995 Solid State Ionics $\mathbf{7 6} 15$

Zavalij P Y and Whittingham M S 1999 Acta Crystallogr. B55 627 